\title{
Protein profiling of osteosarcoma tissue and soft callus unveils activation of the unfolded protein response pathway
}

\author{
PARUNYA CHAIYAWAT ${ }^{1}$, PATSADAKORN SUNGNGAM ${ }^{1}$, PIMPISA TEEYAKASEM ${ }^{1}$, NUTNICHA SIRIKAEW ${ }^{1}$, \\ JEERAWAN KLANGJORHOR ${ }^{1}$, JONGKOLNEE SETTAKORN ${ }^{2}$, PENCHATR DISKUL-NA-AYUDTHAYA $^{3}$, \\ DARANEE CHOKCHAICHAMNANKIT ${ }^{3}$, CHANTRAGAN SRISOMSAP $^{3}$, \\ JISNUSON SVASTI ${ }^{3,4}$ and DUMNOENSUN PRUKSAKORN ${ }^{1,5}$ \\ ${ }^{1}$ Musculoskeletal Science and Translational Research Center, Department of Orthopedics, Faculty of Medicine, Chiang Mai \\ University; ${ }^{2}$ Department of Pathology, Faculty of Medicine, Chiang Mai University, Chiang Mai 50200; \\ ${ }^{3}$ Laboratory of Biochemistry, Chulabhorn Research Institute; ${ }^{4}$ Applied Biological Science, Chulabhorn Graduate Institute, \\ Chulabhorn Royal Academy, Bangkok 10210; ${ }^{5}$ Biomedical Engineering Institute, \\ Chiang Mai University, Chiang Mai 50200, Thailand
}

Received October 4, 2018; Accepted February 7, 2019

DOI: $10.3892 /$ ijo.2019.4737

\begin{abstract}
Oncogenic drivers of osteosarcoma remain controversial due to the complexity of the genomic background of the disease. There are limited novel therapeutic options, and the survival rate of patients with osteosarcoma has not improved in decades. Genomic instability leads to complexity in various pathways, which is potentially revealed at the protein level. Therefore, the present study aimed to identify the mechanisms involved in the oncogenesis of osteosarcoma using proteomics and bioinformatics tools. As clinical specimens from patients are the most relevant disease-related source, expression patterns of proteins in osteosarcoma tissues were compared with soft tissue callus from donors containing high numbers of osteoblastic cells. Two-dimensional electrophoresis and liquid chromatography-tandem mass spectrometry (LC-MS/MS) successfully identified 33 differentially expressed proteins in the osteosarcoma tissues compared with the soft tissue callus. Among these proteins, 29 proteins were significantly upregulated in osteosarcoma. A functionally grouped network of the overexpressed proteins, that was created using the ClueGo and CluePedia applications, demonstrated that the unfolded protein response (UPR) pathway was activated mainly through the activating transcription factor 6 arm in osteosarcoma. The results of proteomics analysis were confirmed by elevated
\end{abstract}

Correspondence to: Dr Dumnoensun Pruksakorn, Musculoskeletal Science and Translational Research Center, Department of Orthopedics, Faculty of Medicine, Chiang Mai University, 110 Inthawarorot Road, Chiang Mai 50200, Thailand

E-mail: dumnoensun.p@cmu.ac.th

Key words: bone neoplasms, proteomics, bony callus, heat-shock proteins, molecular chaperone, $78 \mathrm{kDa}$ glucose-regulated protein expression of UPR-related chaperone proteins, including $78 \mathrm{kDa}$ glucose-related protein (GRP78), endoplasmin, calreticulin and prelamin-A/C, in the patient-derived primary cells and osteosarcoma cell lines. Furthermore, the expression of GRP78, a master regulator of the UPR, was enhanced in the osteosarcoma tissues of patients that were resistant to double regimen of doxorubicin and a platinum-based drug. The findings of the present study suggest that targeting the UPR pathway may be promising for the treatment of osteosarcoma.

\section{Introduction}

Osteosarcoma is an aggressive malignant tumor of bone, which is mainly observed in children and adolescents (1). Up to $70 \%$ of patients with osteosarcoma are treated with multimodal therapies that include chemotherapy [such as doxorubicin (DOX), methotrexate and cisplatin] and surgical excision (2,3). However, over the past three decades, survival rates have not substantially improved. Furthermore, there is a lack of effective therapeutic options for patients suffering from a recurrence and metastasis of the disease. The lack of options is mainly due to the complicated etiologies of the disease, which are responsible for an extremely complex genomic organization that results from chromosome aberrations, chromothripsis, kataegis, and genome instability with a high rate of copy number alterations and structural variations $(4,5)$. In addition, accumulating evidence indicates that there are epigenetic changes in osteosarcoma, mainly through histone modifications and DNA methylation (6). This aberrance induces significant alterations in the expression levels of various oncogenic proteins and tumor suppressors in osteosarcoma (7-10). The intricate heterogeneity introduces difficulties for the identification of key oncogene-driven pathways, which may be potential targets for effective treatment of osteosarcoma.

While genomics provide an insight into the molecule profile of cancer, which indicates key players in the tumorigenesis and progression of the disease, proteomics connects the 
genomic information with disease phenotypes. Defects at the genomic level affect cellular function and regulation, which are revealed at the protein level. Recent advances in current proteomic techniques and bioinformatics allow detailed and more complete views of biological networks relating to disease.

Cancer patient tissue is an ideal biological specimen for studying disease etiology at the genomic and proteomic levels as it most accurately represents the subject. In addition, the method of fresh freezing is a compatible preservation procedure for subsequent proteomic analysis. Therefore, in the present study, proteomics analysis using freshly frozen biopsy tissues from patients with osteosarcoma was performed. Due to the pathophysiology of osteosarcoma, one of limitations in a proteomics study is that there are no adequate comparable control tissues. To date, the majority of proteomic studies of osteosarcoma tissues have been performed using clinical specimens from patients compared with benign bone tumors $(11,12)$. No consensus representative normal tissues have been defined. In the present study, soft tissue callus was used as a non-cancerous control tissue. Soft callus is formed during the normal fracture repair process primarily from periosteal cells, which are the major source of osteoblasts and chondrocytes $(13,14)$. Bone callus has been demonstrated to contain the highest density of active osteoblasts at 3 months after a fracture, and then the density decreases over time (15). Thus, soft callus is a good source of non-cancerous tissue containing high numbers of osteoblastic cells that can be used as a control in a proteomics study of osteosarcoma.

The aim of the present study was to obtain novel information regarding osteosarcoma mechanisms by studying protein patterns directly from clinical tissues together with bioinformatics tools. The findings suggest disease-relevant pathways that may serve as novel targets for the treatment of osteosarcoma.

\section{Materials and methods}

Patients and tissue samples. Chemonaïve osteosarcoma tissues were obtained from patients diagnosed and treated at Maharaj Nakorn Chiang Mai Hospital (Chiang Mai, Thailand). Soft tissue callus was collected from donors who were treated at the Trauma Unit, Maharaj Nakorn Chiang Mai Hospital. All tissue samples were freshly frozen and stored at $-80^{\circ} \mathrm{C}$ until use. Patients, or parents in the case of minors, and volunteers gave written consent to be included in the study. This study was approved by the Research Ethics Committee of the Faculty of Medicine, Chiang Mai University (Chiang Mai, Thailand). All clinicopathological parameters were retrieved from hospital records and pathology reports (Table I).

Two-dimensional electrophoresis (2DE) of proteins from osteosarcoma and soft callus tissues. Osteosarcoma and soft callus tissues were lysed in radioimmunoprecipitation assay buffer supplemented with $1 \%$ protease inhibitor (Sigma-Aldrich; Merck KGaA, Darmstadt, Germany), homogenized and incubated on ice for $30 \mathrm{~min}$. The supernatant was collected by centrifugation at $15,000 \mathrm{x}$ g at $4^{\circ} \mathrm{C}$ for $20 \mathrm{~min}$. Crude tissue lysates were further prepared for $2 \mathrm{DE}$ analysis using a 2-D Clean-Up kit, according to the manufacturer's protocol (GE Healthcare Life Sciences, Uppsala, Sweden). Protein concentration was determined using Bradford assay.
The protein pellets were resuspended in 2D lysis buffer. Individual samples (60 $\mu$ g protein) were applied by overnight in-gel rehydration of $7 \mathrm{~cm} \mathrm{pH} \mathrm{3-10} \mathrm{nonlinear} \mathrm{gradient} \mathrm{IPG}$ strips (GE Healthcare, Chicago, IL, USA). IEF was performed at 7,000 Vh, $55 \mathrm{~mA}$ per gel strip using an Ettan IPGphor 3 (GE Healthcare). The IPG strips were equilibrated and separated in 14\% SDS-PAGE followed by SYPRO Ruby staining (Thermo Fisher Scientific, Inc., Waltham, MA, USA), as previously described (16). Gels were scanned and visualized using Ettan DIGE Imager (GE Healthcare).

Spot detection and analysis. To minimize contamination by the highly abundant protein present in the tissue samples, the protein spots on the 2DE gels were aligned to human serum protein patterns, as previously reported (17). Major highly abundant proteins, including $\alpha$ and $\gamma$ Ig heavy chain, serum albumin, hemoglobin $\beta$ chain, complement factor $B$ and transferrin, were observed in every $2 \mathrm{DE}$ gel. The volume of abundant proteins present was subtracted from the total volume of all protein spots on individual gels. The gels were then analyzed using ImageMaster 2D Platinum 7.0 software (GE Healthcare). The relative volume (\%) of a spot was used to compare differences in the expression of each protein between the osteosarcoma and soft callus tissues. In addition to strict control of sample preparation and the experimental procedure of the first- and second-dimension separation, statistical analyses were applied in order to minimize experimental variations and increase the reliability and overall reproducibility of the 2DE results. Each gel of the osteosarcoma tissues (4 cases) was independently compared to each gel from the soft tissue callus (4 cases), generating 16 match sets in total. Only spots that were consistently upregulated or downregulated in $\geq 80 \%$ of all match sets and significantly different by $\geq 1.5$-fold $(\mathrm{P}<0.05$, Student's t-test) were subjected to protein identification.

In-gel digestion. The protein spots from the osteosarcoma tissues were excised and subjected to in-gel trypsin digestion, as previously described (16). Briefly, the excised gels were destained with $50 \% \mathrm{ACN}$ in $0.1 \mathrm{M} \mathrm{NH}_{4} \mathrm{HCO}_{3}$, reduced with $10 \mathrm{mM}$ DTT, alkylated in $100 \mathrm{mM}$ iodoacetamide and digested with trypsin (Promega Corporation, Madison, WI, USA) at $37^{\circ} \mathrm{C}$ overnight. The digested peptides were dried and collected for protein identification by liquid chromatography-tandem mass spectrometry (LC-MS/MS).

Protein identification by $L C-M S / M S$. The digested peptides were identified using nanoflow liquid chromatography coupled with nano ESI MS/MS (Q-TOF micro) (both from Waters Corporation, Milford, MA, USA). The MS/MS spectra were processed using MassLynx 4.0 software (Waters Corporation) and converted to PKL files using ProteinLynx 2.2 software (Waters Corporation). Protein identification was performed using the Mascot search engine with NCBInr version 20130630 sequence and SwissProt databases (http://www.matrixscience.com). The search parameters were set as follows: Peptide mass tolerance, 1.2 Da; MS/MS ion mass tolerance, $0.2 \mathrm{Da}$; allowance, 1 missed cleavage; enzyme, trypsin; and limit of peptide charges, $1^{+}, 2^{+}$and $3^{+}$. Proteins identified with $\mathrm{P} \leq 0.05$ were considered as promising hits. Proteins with a molecular weight and pI consistent with 
Table I. Characteristics of osteosarcoma patients and donors.

\begin{tabular}{|c|c|c|c|c|c|c|c|}
\hline Sample ID & Sex & $\begin{array}{c}\text { Age at } \\
\text { diagnosis }\end{array}$ & Site & $\begin{array}{l}\text { Enneking } \\
\text { stage }\end{array}$ & $\begin{array}{l}\text { Neoadjuvant } \\
\text { chemotherapy }\end{array}$ & $\begin{array}{l}\% \text { tumor } \\
\text { necrosis }\end{array}$ & $\begin{array}{l}\text { Lung } \\
\text { metastasis }\end{array}$ \\
\hline \multicolumn{8}{|c|}{ Osteosarcoma } \\
\hline OS1 & Male & 24 & Distal femur & IIB & DOX/Ifos & 80 & Yes \\
\hline OS2 & Female & 15 & Proximal humerus & IIB & - & 10 & No \\
\hline OS3 & Male & 12 & Proximal tibia & IIB & MTX NA & No & \\
\hline OS4 & Female & 5 & Distal femur & IIB & DOX/CIS/MTX & 10 & Yes \\
\hline OS5 & Female & 9 & Distal femur & IIB & DOX/Carbo & 90 & No \\
\hline OS6 & Female & 15 & Distal femur & IIB & DOX/CIS & 90 & No \\
\hline OS7 & Female & 11 & Distal femur & IIB & ICE & 95 & No \\
\hline OS8 & Female & 5 & Distal femur & IIB & DOX/CIS/MTX & 10 & Yes \\
\hline OS9 & Male & 15 & Distal femur & IIB & DOX/CIS & 42 & Yes \\
\hline OS 10 & Female & 61 & Distal femur & IIB & DOX/CIS & 35 & Yes \\
\hline OS11 & Male & 12 & Proximal tibia & III & DOX/CIS/MTX & 95 & Yes \\
\hline OS12 & Female & 54 & Ilium & III & DOX/CIS & 50 & Yes \\
\hline OS13 & Female & 13 & Proximal humerus & III & - & NA & Yes \\
\hline \multicolumn{8}{|c|}{ Soft callus and osteoblast } \\
\hline Cal1 & Female & 58 & Distal femur & - & - & - & - \\
\hline $\mathrm{Cal} 2$ & Female & 36 & Distal femur & - & - & - & - \\
\hline Cal3 & Female & 64 & Distal femur & - & - & - & - \\
\hline Cal4 & Male & 28 & Distal femur & - & - & - & - \\
\hline Cal5 & Male & 19 & Tibia & - & - & - & - \\
\hline Cal6 & Male & 26 & Proximal femur & - & - & - & - \\
\hline Cal7 & Male & 17 & Shaft femur & - & - & - & - \\
\hline Cal8 & Male & 32 & Shaft femur & - & - & - & - \\
\hline
\end{tabular}

DOX, doxorubicin; Ifos, ifosfamide; MTX, methotrexate; CIS, cisplatin; Carbo, carboplatin; ICE, ifosfamide, carboplatin and etoposide.

the spots on the 2DE gels were considered to be positively identified.

Gene ontology (GO) terms enrichment and pathway analysis. Functional enrichment analysis of the upregulated proteins in osteosarcoma was performed using WebGestalt (18). ClueGO (version 2.3.3) and CluePedia (version 1.3.3), a plugin for Cytoscape version 3.4, were used for functionally grouped network analysis $(19,20)$.

Primary cell extraction and characterization. Primary osteoblastic cells were isolated from bone grafts of patients who had been diagnosed with non-cancerous orthopedic conditions and required the use of autologous bone grafts as substitution procedures. Primary osteoblasts used in this study were derived from a set of bone graft specimens previously reported (6). Primary osteosarcoma cells were extracted from chemonaïve biopsy tissues of patients with osteosarcoma. Extraction, culturing and characterization of the primary cells were performed according to previously described protocols (21). Briefly, the primary cells were isolated by incubating the tissues in $5 \mathrm{mg} / \mathrm{ml}$ collagenase type I solution (Gibco; Thermo Fisher Scientific, Inc.) at $37^{\circ} \mathrm{C}$ for $18 \mathrm{~h}$. The cells were pelleted by centrifugation and cultured in freshly prepared Dulbecco's modified Eagle's medium (DMEM) with 10\% fetal bovine serum (FBS;
Gibco; Thermo Fisher Scientific, Inc.) at $37^{\circ} \mathrm{C}$ in a humidified $5 \% \mathrm{CO}_{2}$ incubator. All primary cells were characterized for doubling time and osteogenicity. Cancer markers, including matrix metallopeptidase (MMP)-9 and collagen type X, were determined by reverse transcription-quantitative polymerase chain reaction, according to a previously described protocol (21).

Cell culture. Osteosarcoma and osteoblastic cell lines used in this study include MNNG/HOS (CLS 300289; Cell Lines Service, GmbH, Eppelheim, Germany), U2OS (CLS-300364; Cell Lines Service, GmbH), 143B (CRL-8303; ATCC, Manassas, VA, USA), MG-63 (CRL-1427; ATCC), Saos-2 (HTB-85; ATCC) and normal human osteoblast cell line hFOB1.19 (CRL-11372; ATCC). MNNG/HOS was cultured in Roswell Park Memorial Institute (RPMI)-1640 medium supplemented with $10 \%$ FBS (Gibco; Thermo Fisher Scientific, Inc.). MG-63 was cultured in DMEM supplemented with 10\% FBS. 143B cells was cultured in DMEM supplemented with $10 \%$ FBS and $0.015 \mathrm{mg} / \mathrm{ml}$ 5-bromo-2'-deoxyuridine (Merck KGaA). U2OS, Saos-2 and hFOB1.19 were cultured in F-12 Medium supplemented with $10 \%$ FBS. All the cells were maintained at $37^{\circ} \mathrm{C}$ in humidified $5 \% \mathrm{CO}_{2}$ incubator.

Western blot analysis and total protein staining. Crude proteins were extracted from osteosarcoma cells and 
tissue samples, as well as osteoblastic cells and soft callus tissues, with RIPA buffer supplemented with $1 \%$ protease inhibitor cocktail (Amresco, LLC, Solon, OH, USA). Protein concentration was determined by Bradford assay. Extracted proteins $(10-15 \mu \mathrm{g})$ were separated in $10 \%$ SDS-PAGE and transferred to polyvinylidene difluoride (PVDF) membranes (Immobilon-P; EMD Millipore, Billerica, MA, USA). Protein bands on the blots of tissue samples were stained using $0.15 \%$ (w/v) Ponceau S dye (Sigma-Aldrich; Merck KGaA) in $1 \%$ acetic acid. The protein images were used to control protein loading by quantifying the whole lane of protein bands. The membranes were destained in TBS/T (TBS, $0.1 \%$ Tween-20) for 5 min. After blocking with $10 \%$ skimmed milk in TBS/T, membranes were incubated with antibodies specific to GRP78 (1:1,000; cat. no. ab108615), GRP94 (1:1,000; cat. no. ab108606), prelamin-A/C (1:5,000; cat. no. ab169532), and calreticulin (1:2,000; cat. no. ab22683) (all from Abcam, Cambridge, UK) at $4{ }^{\circ} \mathrm{C}$ overnight. Membranes were then washed with TBS/T, and incubated with secondary antibody conjugated with horseradish peroxidase (HRP; 1:5,000; cat. no. ab6721; Abcam) at room temperature for $1 \mathrm{~h}$. Bands on immunoblots were detected using ECL-Advance Western Blotting Detection kit (GE Healthcare).

$R T-q P C R$. RNA was extracted from osteosarcoma and osteoblastic cells using Ilustra RNAspin Mini kit (GE Healthcare), and cDNA was synthesized from total RNA using a Bioline SensiFAST cDNA synthesis kit (Bioline, London, UK). qPCR was performed in Chromo4 Real-Time PCR Detection system (Bio-Rad Laboratories, Inc., Hercules, CA, USA) using a Bioline SensiFAST SYBR No-ROX kit (Bioline). To compare the mRNA expression of each group, $\beta$-actin was used as an internal control. The primers used were: sliced X-box binding protein 1 (XBP1s), forward, 5'-TGCTGAGTCCGCAGCAGGTG-3' and reverse, 5'-GCTGGCAGGCTCTGGGGAAG-3' (22); $\beta$-actin, forward, 5'-TTCAACACCCCAGCCATGT-3' and reverse, 5'-TGGTAC GGCCAGAGGCGTACAG-3'; MMP-9, forward, 5'-TGAGAAC CAATCTCACCGACAG-3' and reverse, 5'-TGCCACCCGAG TGTAACCAT-3'; collagen type X, forward, 5'-AGGAATGCC TGTGTCTGCTT-3' and reverse, 5'-ACAGGCCTACCCAA ACATGA-3'; collagen type I, forward, 5'-CAGCCGCTTCACC TACAGC-3' and reverse, 5'-TTTTGTATTCAATCACTGTCTT GCC-3'; osteonectin, forward, 5'-TCCACAGTACCGGATT CTCTCT-3' and reverse, 5'-TCTATGTTAGCACCTTGTCTC CAG-3'; and bone sialoprotein, forward, 5'-GCAGTAGTGAC TCATCCGAAGAA-3' and reverse, 5'-GCCTCAGAGTCT TCATCTTCATTC-3'. The thermal profile was set according to previous report as follows: initial incubation step at $95^{\circ} \mathrm{C}$ for $3 \mathrm{~min}$, followed by 40 cycles of denaturation at $95^{\circ} \mathrm{C}$ for $10 \mathrm{sec}$, annealing at $62^{\circ} \mathrm{C}$ for $15 \mathrm{sec}$, and extension at $72^{\circ} \mathrm{C}$ for $30 \mathrm{sec}(22)$. Relative fold changes in mRNA expression were calculated using the $2^{-\Delta \Delta C q}$ method (23).

Statistical analysis. Data are presented as means \pm standard deviation with three independent replications. Statistical analyses were performed using GraphPad Prism version 8.0 (GraphPad Software, Inc., La Jolla, CA, USA). The significance of the differential expression of UPR-related proteins and XBP1s in multiple cells and tissues was tested using one-way analysis of variance followed by Bonferroni's test. The difference between two groups was tested using Student's t-test for parametric tests and the Mann-Whitney $\mathrm{U}$ test for nonparametric tests. $\mathrm{P}<0.05$ was considered to indicate a statistically significant difference.

\section{Results}

Histological evaluation of osteosarcoma tissue and soft tissue callus. A representative image of the osteosarcoma tissue from the proximal tibias of patients who had undergone amputation is shown in Fig. 1A. The white fresh tissue extruding from destructive metaphyseal was harvested. Soft callus was derived from the fracture site of donors who were treated at the Trauma Unit. Soft callus appears as soft fresh tissue covering the fracture site, as illustrated in Fig. 1B. Formalin-fixed paraffin-embedded sections of osteosarcoma tissue and soft tissue callus were stained with hematoxylin and eosin and evaluated by an experienced musculoskeletal pathologist. Histologically, the osteosarcoma tissue exhibited high cellularity and consisted of malignant plump spindle cells with osteoid matrix production (Fig. 1C). The staining of the soft callus demonstrated a high content of osteoblastic cells (Fig. 1D).

Identification of differentially expressed proteins in osteosarcoma tissues in comparison to soft tissue callus using $2 D E$ and $L C-M S / M S$. In the protein profiling of the chemonaïve tissues derived from patients with osteosarcoma (4 cases; OS1-4) and soft tissue callus from donors (4 cases; Cal1-4), 2DE was used to analyze the protein extracted from the individual samples. The characteristics of all patients and donors are presented in Table I. The protein spots on the individual 2DE gels from the osteosarcoma tissues and soft tissue callus were matched, generating a total of 16 match sets (Fig. 2).

A total of 329 protein spots were perfectly matched between the osteosarcoma and soft callus tissues. Overall, 28 proteins were upregulated and 4 proteins were downregulated in osteosarcoma compared with soft tissue callus $(\geq 1.5$-fold change, $\mathrm{P}<0.05$; Fig. $3 \mathrm{~A}$ and $\mathrm{B}$ ). One protein spot was specifically present in the osteosarcoma tissues but not in the soft callus tissues. The differences between the volume of each protein spot in the osteosarcoma and soft callus tissues were mostly consistent among the match sets (Fig. 3C). The average fold changes of each protein spot are illustrated in Fig. 3D. All protein spots with $\geq 1.5$-fold change were cut, digested with trypsin, and subjected to LC-MS/MS analysis. The protein identification is presented in Table II.

Enrichment analysis of GO terms of the upregulated proteins in osteosarcoma. The WebGestalt web tool was used to determine the enriched biological processes, cellular components and molecular functions of the upregulated proteins in osteosarcoma. Of the 29 upregulated proteins, the majority were involved in metabolic processes, biological regulation, and response to stimulus (Fig. 4). Major localizations of the upregulated proteins included the secretory vesicle, nucleus, cytosol and membrane (Fig. 4). Furthermore, the majority of the observed proteins appear to have functions in protein binding (Fig. 4).

Pathway analysis of the upregulated proteins in osteosarcoma. To further investigate the functionally grouped networks of 

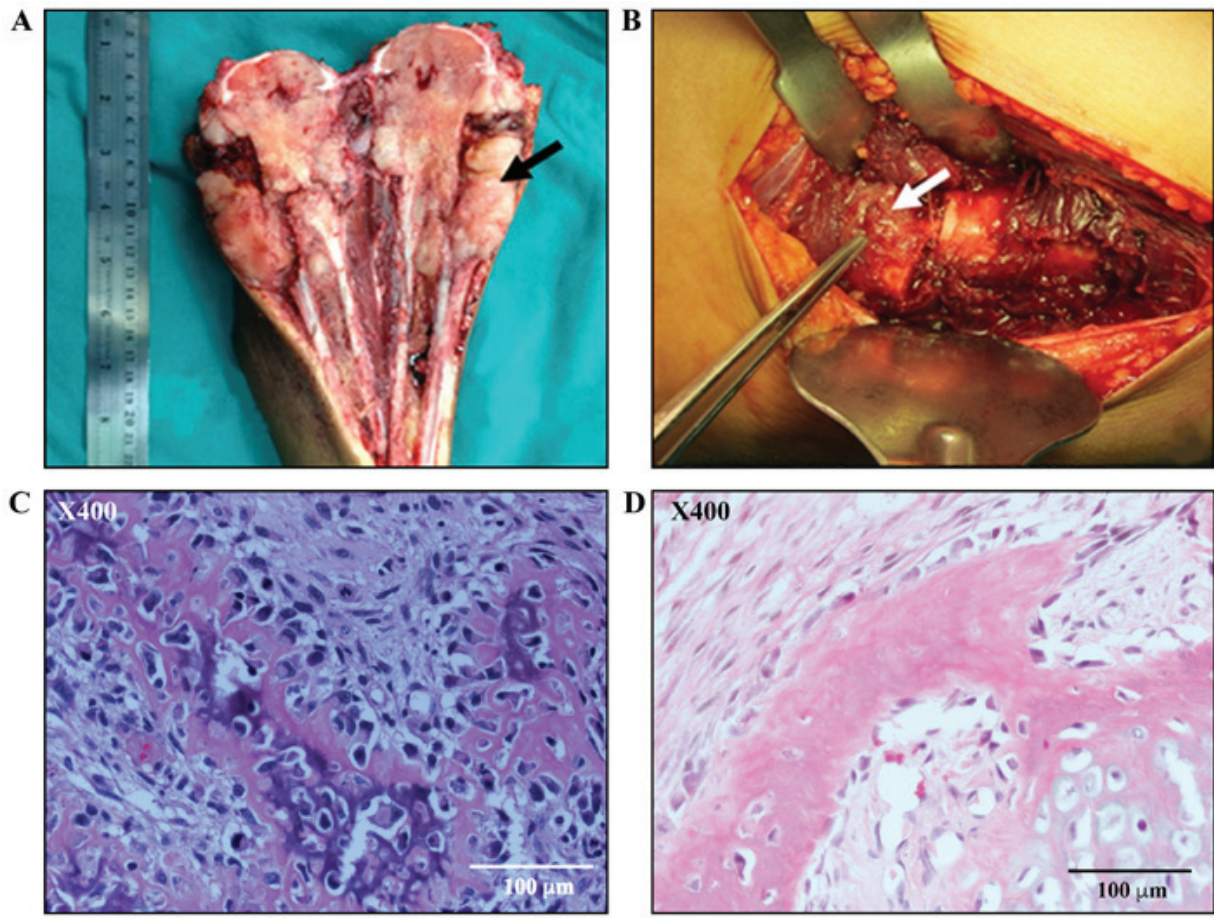

Figure 1. Histology of osteosarcoma and soft callus tissues. (A) Gross specimen of an osteosarcoma mass (indicated by the black arrow). (B) Soft callus formation at the fracture site (indicated by the white arrow). (C) Hematoxylin and eosin staining of osteosarcoma and (D) soft callus tissues (magnification, $\mathrm{x} 400$ ).

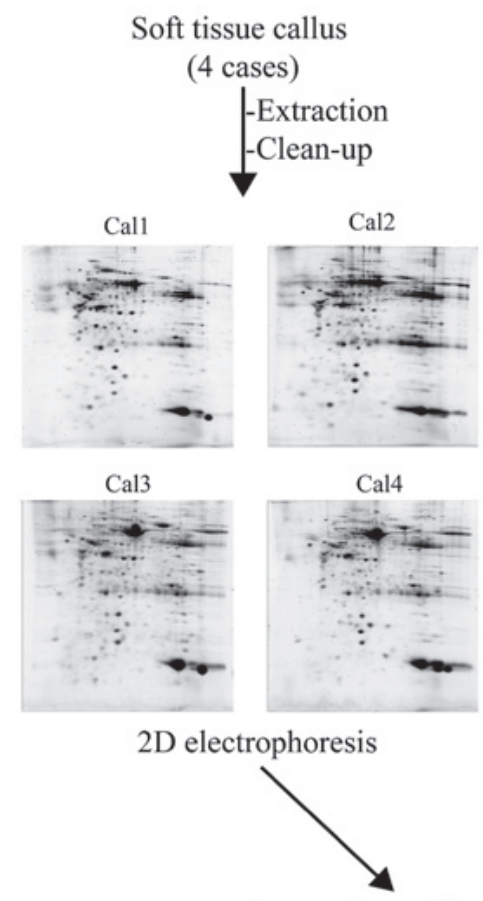

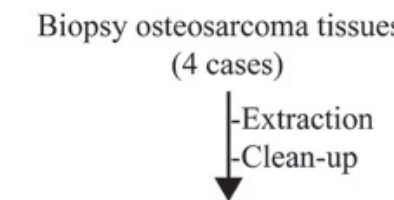

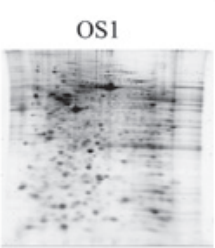

OS3

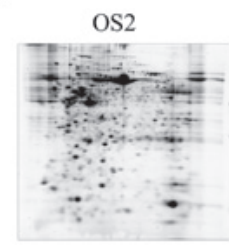

OS4
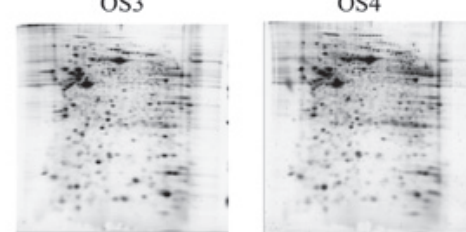

2D electrophoresis

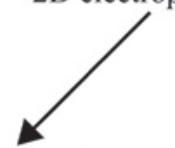

Comparison of intensity of protein spots in each match set

\begin{tabular}{|c|c|c|c|c|}
\hline Sample & Cal1 & Cal2 & Cal3 & Cal4 \\
\hline OS1 & Match1 & Match5 & Match9 & Match13 \\
\hline OS2 & Match2 & Match6 & Match10 & Match14 \\
\hline OS3 & Match3 & Match7 & Match11 & Match15 \\
\hline OS4 & Match4 & Match8 & Match12 & Match16 \\
\hline \multicolumn{5}{|c}{} \\
\\
LC-MS/MS
\end{tabular}

Figure 2. Flow chart of the experimental design for 2DE analysis of osteosarcoma tissues and soft tissue callus. The intensity of the protein spots on individual gels was cross-matched and comparisons were made between the osteosarcoma tissue samples (OS1-4) and the soft tissue callus samples (Cal1-4). The spots of the differentially expressed proteins were digested to short peptides prior to being analyzed by LC-MS/MS. 2DE, two-dimensional electrophoresis; LC-MS/MS, liquid chromatography-tandem mass spectrometry. 
Table II. Identification of differentially expressed proteins in osteosarcoma tissues compared with soft callus tissues.

\begin{tabular}{|c|c|c|c|c|c|c|c|c|c|}
\hline $\begin{array}{l}\text { Spot } \\
\text { no. }{ }^{a}\end{array}$ & $\begin{array}{c}\text { Accession } \\
\text { no. }\end{array}$ & Name & Gene & $\mathrm{MW} / \mathrm{pI}^{\mathrm{b}}$ & Score $^{c}$ & $\begin{array}{l}\text { Peptide } \\
\text { match }^{\mathrm{d}}\end{array}$ & $\begin{array}{l}\text { Coverage }^{\mathrm{e}} \\
(\%)\end{array}$ & Regulation & $\begin{array}{c}\text { Fold change }{ }^{\mathrm{f}} \\
\text { (mean } \pm \text { standard } \\
\text { error) }\end{array}$ \\
\hline 1 & P58546 & Myotrophin & MTPN & $12.89 / 5.27$ & 71 & 3 & 14 & Up & $\uparrow 2.76 \pm 0.28$ \\
\hline 11 & P62937 & $\begin{array}{l}\text { Peptidyl-prolyl cis-trans } \\
\text { isomerase A, Cyclophilin }\end{array}$ & PPIA & $18.00 / 7.68$ & 93 & 3 & 10 & Up & $\uparrow 3.40 \pm 0.24$ \\
\hline 14 & P30086 & $\begin{array}{l}\text { Phosphatidylethanolamine- } \\
\text { binding protein } 1\end{array}$ & PEBP1 & $21.04 / 7.01$ & 45 & 2 & 8 & Up & $\uparrow 2.73 \pm 0.39$ \\
\hline 21 & P28070 & Proteasome subunit $\beta$ type- 4 & PSMB4 & $29.18 / 5.72$ & 79 & 2 & 7 & Up & $\uparrow 1.77 \pm 0.25$ \\
\hline 31 & P00338 & $\begin{array}{l}\text { L-lactate dehydrogenase A } \\
\text { chain }\end{array}$ & LDHA & $36.66 / 8.44$ & 69 & 4 & 11 & Up & $\uparrow 5.32 \pm 0.96$ \\
\hline 34 & P04083 & Annexin A1 & ANXA1 & $38.69 / 6.57$ & 82 & 2 & 6 & Up & $\uparrow 4.75 \pm 0.66$ \\
\hline 40 & P04075 & $\begin{array}{l}\text { Fructose-bisphosphate } \\
\text { aldolase A }\end{array}$ & ALDOA & $39.40 / 8.30$ & 71 & 5 & 11 & Up & $\uparrow 3.40 \pm 0.58$ \\
\hline 45 & P31930 & $\begin{array}{l}\text { Cytochrome b-c1 complex } \\
\text { subunit } 1\end{array}$ & UQCRC1 & $52.61 / 5.94$ & 72 & 4 & 7 & Up & $\uparrow 1.51 \pm 0.46$ \\
\hline 51 & Q04917 & $14-3-3$ protein eta & YWHAH & $28.20 / 4.76$ & 101 & 5 & 17 & Up & $\uparrow 2.62 \pm 0.22$ \\
\hline 52 & P67936 & Tropomyosin $\alpha-4$ chain & TPM4 & $28.50 / 4.67$ & 124 & 9 & 26 & Up & $\uparrow 1.78 \pm 0.37$ \\
\hline 68 & P06733 & $\alpha$-enolase & ENO1 & $47.14 / 7.01$ & 177 & 9 & 20 & Up & $\uparrow 2.44 \pm 0.18$ \\
\hline 79 & Q14697 & Neutral $\alpha$-glucosidase AB & GANAB & $106.81 / 5.74$ & 97 & 6 & 5 & Up & $\uparrow 4.04 \pm 0.38$ \\
\hline 86 & P14625 & Endoplasmin & HSP90B1 & $92.41 / 4.76$ & 43 & 2 & 2 & Up & $\uparrow 4.85 \pm 1.01$ \\
\hline 87 & P31949 & Protein S100-A11 & S100A11 & $11.73 / 6.56$ & 50 & 2 & 17 & Up & $\uparrow 3.31 \pm 0.43$ \\
\hline 95 & P28072 & Proteasome subunit $\beta$ type- 6 & PSMB6 & $25.34 / 4.80$ & 70 & 1 & 10 & Up & $\uparrow 2.48 \pm 0.25$ \\
\hline 102 & P09525 & Annexin A4 & ANXA4 & $35.86 / 5.84$ & 71 & 5 & 12 & Up & $\uparrow 2.44 \pm 0.34$ \\
\hline 104 & P08758 & Annexin A5 & ANXA5 & $35.91 / 4.94$ & 57 & 4 & 10 & Up & $\uparrow 2.23 \pm 0.24$ \\
\hline 107 & P47755 & $\begin{array}{l}\text { F-actin-capping protein } \\
\text { subunit } \alpha-2\end{array}$ & CAPZA2 & $32.93 / 5.57$ & 74 & 3 & 10 & Up & $\uparrow 2.08 \pm 0.32$ \\
\hline 108 & P07195 & $\begin{array}{l}\text { L-lactate dehydrogenase B } \\
\text { chain }\end{array}$ & LDHB & $36.62 / 5.71$ & 253 & 10 & 29 & Up & $\uparrow 1.79 \pm 0.19$ \\
\hline 157 & P17742 & $\begin{array}{l}\text { Peptidyl-prolyl cis-trans } \\
\text { isomerase A, Cyclophilin A }\end{array}$ & PPIA & $18.00 / 7.68$ & 43 & 1 & 5 & Up & $\uparrow 3.55 \pm 0.47$ \\
\hline 299 & Q9Y3F4 & $\begin{array}{l}\text { Serine-threonine kinase } \\
\text { receptor-associated protein }\end{array}$ & STRAP & $38.41 / 4.98$ & 69 & 5 & 14 & Up & $\uparrow 1.91 \pm 0.25$ \\
\hline 354 & P51157 & Ras-related protein Rab- 28 & RAB28 & $24.83 / 5.70$ & 49 & 1 & 4 & Up & $\uparrow 2.47 \pm 0.24$ \\
\hline 361 & P02545 & Prelamin-A/C & LMNA & $74.10 / 6.57$ & 255 & 12 & 14 & Up & $\uparrow 2.04 \pm 0.24$ \\
\hline 372 & P10599 & Thioredoxin & TXN & $11.73 / 4.82$ & 84 & 2 & 20 & Up & $\uparrow 2.02 \pm 0.33$ \\
\hline 377 & P26641 & Elongation factor $1-\gamma$ & EEF1G & $50.09 / 6.25$ & 51 & 3 & 5 & & $\uparrow 2.99 \pm 1.17$ \\
\hline 415 & Q9H299 & $\begin{array}{l}\text { SH3 domain binding glutamic } \\
\text { acid-rich-like protein } 3\end{array}$ & SH3BGRL & L310.43/4.82 & 46 & 1 & 10 & Up & $\uparrow 1.46 \pm 0.45$ \\
\hline 537 & P27797 & Calreticulin & CALR & $48.11 / 4.29$ & 68 & 5 & 12 & Up & $\uparrow 2.62 \pm 0.23$ \\
\hline 583 & P11021 & $78 \mathrm{kDa}$ glucose-regulated protein & HSPA5 & $72.29 / 5.07$ & 64 & 9 & 13 & Up & $\uparrow 2.19 \pm 0.29$ \\
\hline 613 & O75874 & $\begin{array}{l}\text { Isocitrate dehydrogenase } \\
{[\mathrm{NADP}] \text { cytoplasmic }}\end{array}$ & IDH1 & $46.63 / 6.53$ & 60 & 3 & 7 & Up & $\uparrow 1.66 \pm 0.19$ \\
\hline 25 & P02647 & Apolipoprotein A-I & APOA1 & $30.76 / 5.56$ & 147 & 10 & 32 & Down & $\uparrow 2.00 \pm 0.33$ \\
\hline 90 & P02766 & Transthyretin & TTR & $15.88 / 5.52$ & 42 & 1 & 8 & Down & $\uparrow 2.81 \pm 0.27$ \\
\hline 93 & P32119 & Peroxiredoxin-2 & PRDX2 & $21.88 / 5.66$ & 113 & 7 & 32 & Down & $\uparrow 3.87 \pm 0.45$ \\
\hline 634 & Q15404 & Ras suppressor protein 1 & RSU1 & $31.52 / 8.57$ & 64 & 1 & 3 & Down & $\uparrow 2.65 \pm 0.29$ \\
\hline A & P05388 & $60 \mathrm{~S}$ acidic ribosomal protein $\mathrm{P} 0$ & RPLP0 & $34.254 / 5.71$ & 48 & 1 & 3 & $\begin{array}{c}\text { Present in } \\
\text { osteosarcoma }\end{array}$ & - \\
\hline
\end{tabular}

a Protein UniProt number; ${ }^{\mathrm{b}}$ molecular weight (kDa) and pI from MASCOT; ${ }^{\mathrm{c}}$ mascot score; ${ }^{\mathrm{d}}$ number of unique peptides identified by MS/MS (multiple matches to peptides with the same primary sequence were counted as one match); ${ }^{\text {e }}$ sequence $\%$ of experimentally identified sequence peptides by tandem mass spectroscopy against unidentified sequence peptides of the same protein; and ${ }^{\mathrm{f}}$ volume ratio of protein spot intensity in osteosarcoma relative to soft callus tissue. 
$\mathbf{A}$

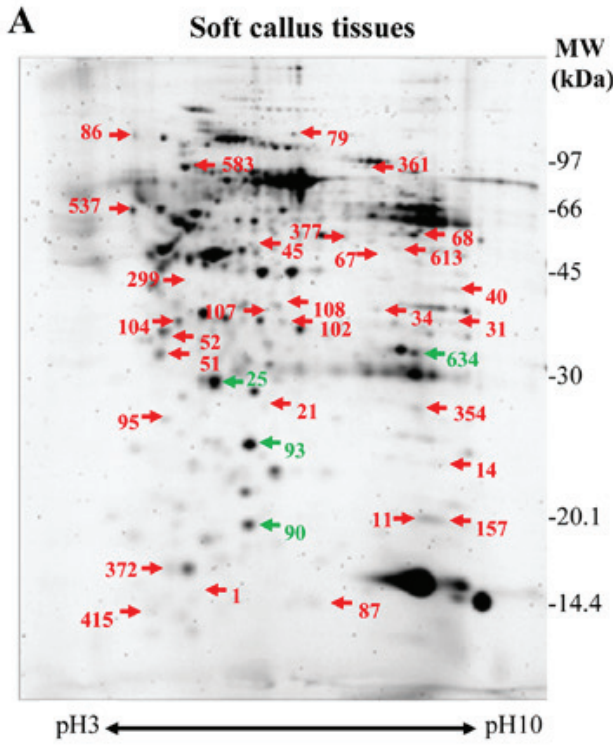

C
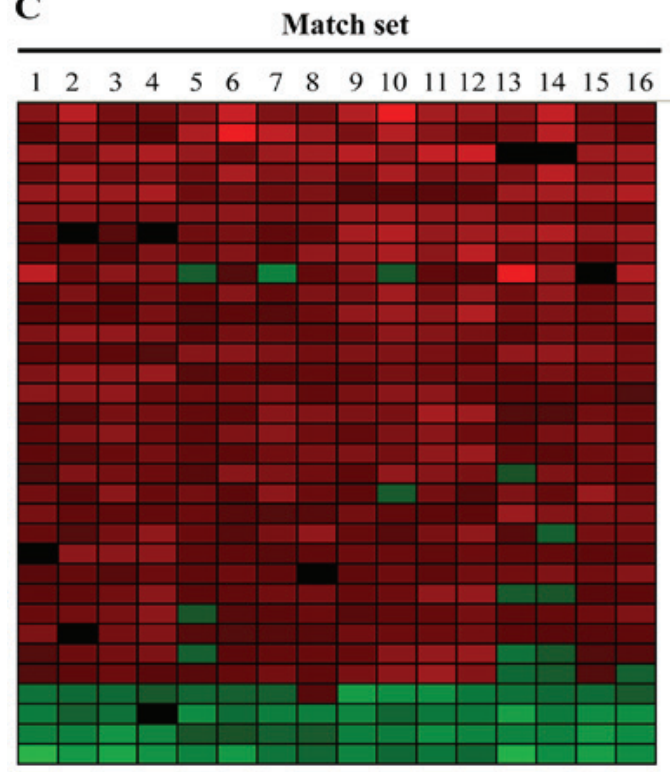

Fold change

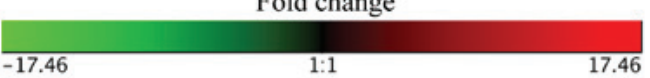

B Osteosarcoma tissues

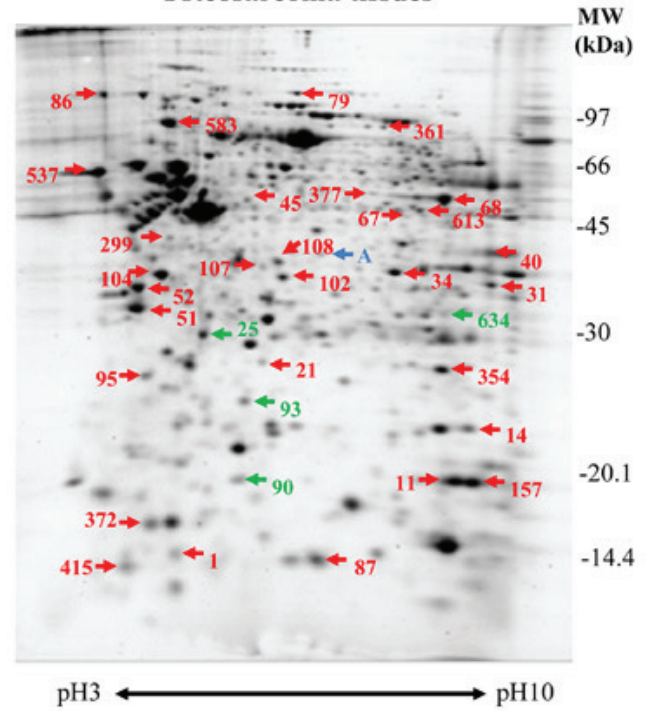

D Differentially expressed proteins in osteosarcoma compared to soft callus tissues ( $\geq 1.5$ fold )

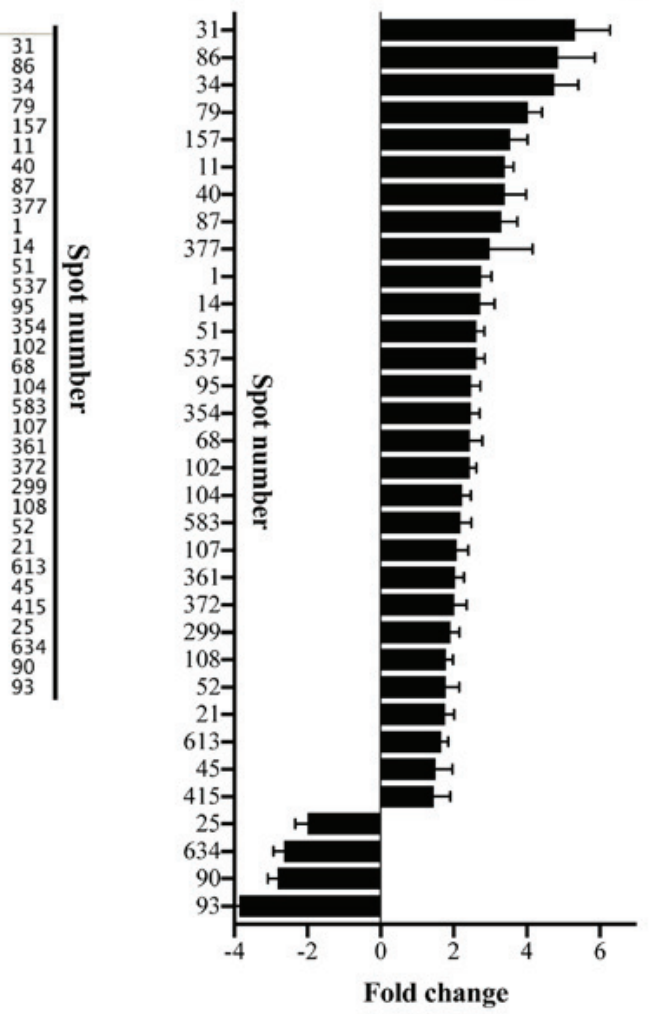

Figure 3. 2DE of osteosarcoma tissues and soft tissue callus. Representative 2DE gels of (A) soft tissue callus and (B) osteosarcoma tissue. The red and green arrows indicate upregulated and downregulated protein spots in the osteosarcoma tissues, respectively. The blue arrow indicates a protein spot that was specifically present in the osteosarcoma tissue but not found in any of the soft tissue callus samples. (C) A heatmap demonstrating the fold change of each protein spot in the osteosarcoma tissues compared with the soft tissue callus in each match set, calculated from the \% volume of the spots. (D) A bar graph presenting the average fold change from the match sets of the protein spots in the osteosarcoma specimens compared with the soft tissue callus. 2DE, two-dimensional electrophoresis.

upregulated proteins in osteosarcoma, the ClueGO and the CluePedia plugins of Cytoscape were used to identify the enriched pathways. ClueGO was used to integrate biological processes, molecular functions, Reactome, Kyoto Encyclopedia of Genes and Genomes (KEGG) pathways and WikiPathways, and to visualize a functionally grouped network. CluePedia was used in conjunction with ClueGO for comprehensive analysis of pathways relating to protein-protein interactions and functions. With the $\kappa$ score level set at $\geq 0.3,22$ terms were found to be connected by 65 edges. Only the statistically significant $(\mathrm{P}<0.05)$ enrichment terms are presented in Fig. 5A. The most significant functional groups included 'activating transcription factor 6 (ATF6; ATF6-alpha) activates chaperone genes', 'phospholipase inhibitor activity', 'glycolysis and 


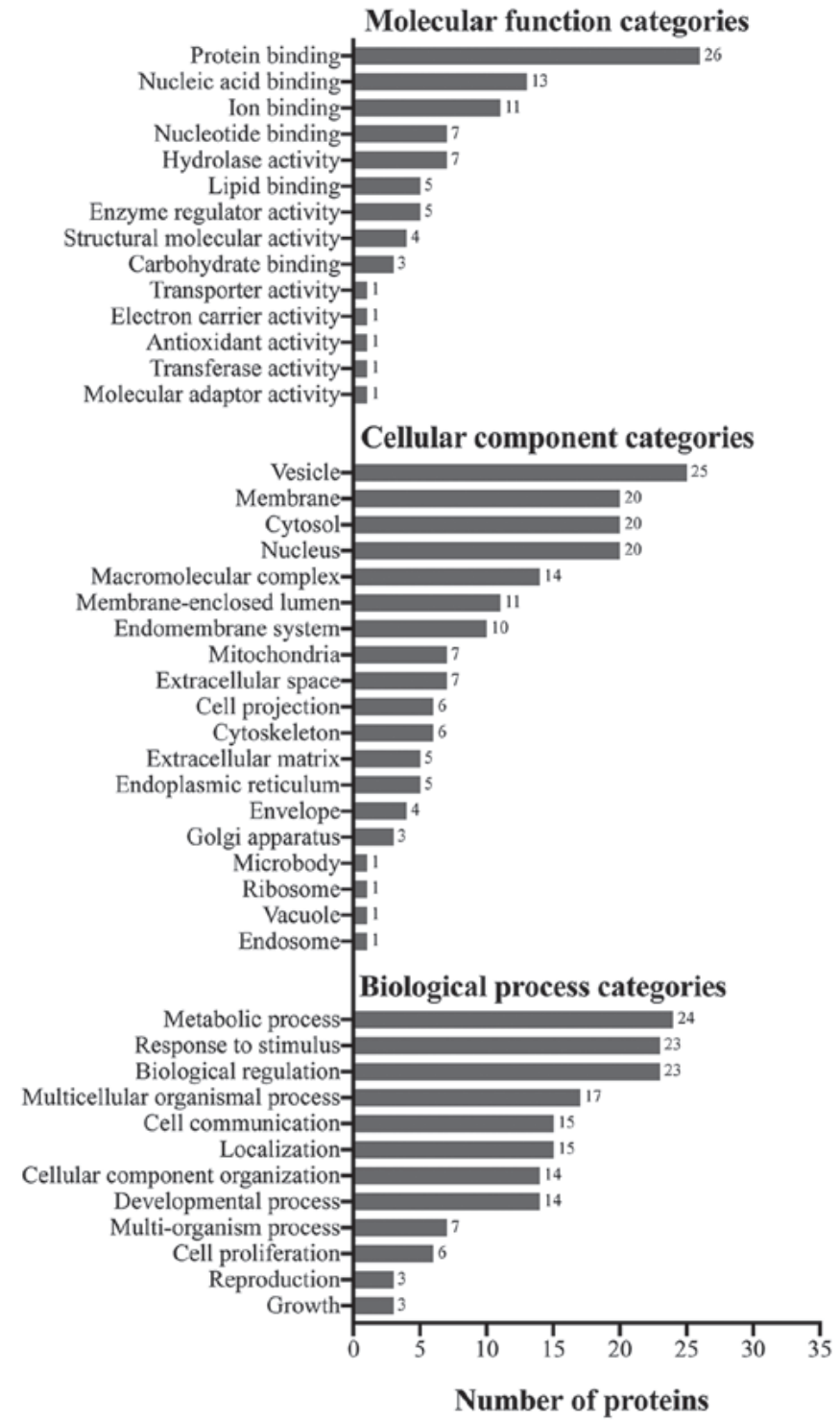

Figure 4. Enriched Gene Ontology terms of the upregulated proteins in the osteosarcoma tissue for the categories of 'biological process', 'cellular compartment' and 'molecular function', as identified using WebGestalt.

gluconeogenesis', 'actin filament depolymerization' and 'substantial nigra development' (Fig. 5B). All GO and pathway terms along with the $\%$ of genes associated with the upregulated proteins in osteosarcoma are presented in Fig. 5C.

Expression of important markers of the unfolded protein response (UPR) pathway is elevated in osteosarcoma cells. The results from the proteomics study demonstrated elevated levels of a number of proteins involved in the UPR pathway. The expression profiles of these proteins, including $78 \mathrm{kDa}$ glucose-regulated protein (GRP78), endoplasmin (GRP94), calreticulin (ERp60) and prelamin-A/C, were validated in osteosarcoma cell lines and in the patient-derived osteosarcoma cells using western blot analysis. As illustrated in Fig. 6A, higher expression levels of GRP78, GRP94 and prelamin-A/C were observed in all osteosarcoma cell lines examined, including MNNG/HOS, 143B, U2OS, Saos-2 and MG-63, compared with the osteoblastic cells hFOB 1.19. A similar trend was also observed in the primary osteosarcoma cells; GRP78, GRP94 and prelamin-A/C were significantly upregulated in the primary osteosarcoma cells (6 cases) compared with the primary osteoblastic cells (5 cases), as illustrated in Fig. 6B. The expression levels of calreticulin were slightly altered in all of the osteosarcoma cell lines and primary cells, but these results were not as significant.

Furthermore, to examine the induction of ER stress and the UPR pathway in osteosarcoma cells, the expression levels of the spliced form of XBP1 mRNA (XBP1s) were measured using RT-qPCR and specific primers to XBP1s mRNA (22). The results demonstrated that XBP1s expression levels were significantly upregulated in most osteosarcoma cells compared with osteoblastic cells (Fig. 6C). Similar results were observed with the patient samples, with primary osteosarcoma cells exhibiting a significantly elevated expression of XBP1s compared with primary osteoblastic cells (Fig. 6D).

Association of UPR-related protein expression levels with clinical outcomes in osteosarcoma. The expression of the four identified proteins was further validated in independent sets of tissues samples that were not used in the original discovery set of the proteomics study. In addition, the expression patterns of these proteins were further investigated in osteosarcoma tissues from patients with different stages of disease, as follows: patients with stage IIB who were sensitive to chemotherapy or good responders (GR; tumor necrosis $\geq 90 \%$ ); patients with stage IIB who responded poorly to chemotherapy (PR; tumor necrosis <90\%); and patients with stage III and initial metastasis (Met). The results demonstrated that the expression of GRP94 was upregulated in the tissues of patients with non-metastasis (stage IIB) and metastasis (stage III) compared with the soft callus controls (Fig. 7A and B). Calreticulin was significantly overexpressed in the patients with stage II. Prelamin-A/C had a tendency towards overexpression in the osteosarcoma tissues. The expression of GRP78 did not differ in the patients with osteosarcoma compared with the soft callus when the patients were classified according to the Enneking staging system. Notably, by considering the expression of GRP78 protein in relation to the chemosensitivity of patients who had received the same chemotherapy regimen (DOX and platinum-based chemotherapy), the results revealed that GRP78 was markedly upregulated in the PR group compared with the soft callus and the GR groups (Fig. 7C).

\section{Discussion}

Fresh frozen tissue is the most biologically representative clinical specimen and is compatible with proteomics analysis. In the present study, upregulated proteins in biopsy tissues from patients with osteosarcoma were identified using $2 \mathrm{DE}$ and LC-MS/MS. Soft tissue callus was used to represent non-cancerous tissue. The formation of soft callus involves chondroblasts and osteoblasts and commonly occurs during the fracture repair process $(24,25)$. In the present study, histological evaluation of osteoblastic morphology in the soft callus was conducted. The results revealed high osteoblastic cell content in the soft callus, suggesting that soft callus is a relevant source of osteoblasts that can represent non-cancerous tissues for proteomics study of osteosarcoma. 
$\mathbf{A}$

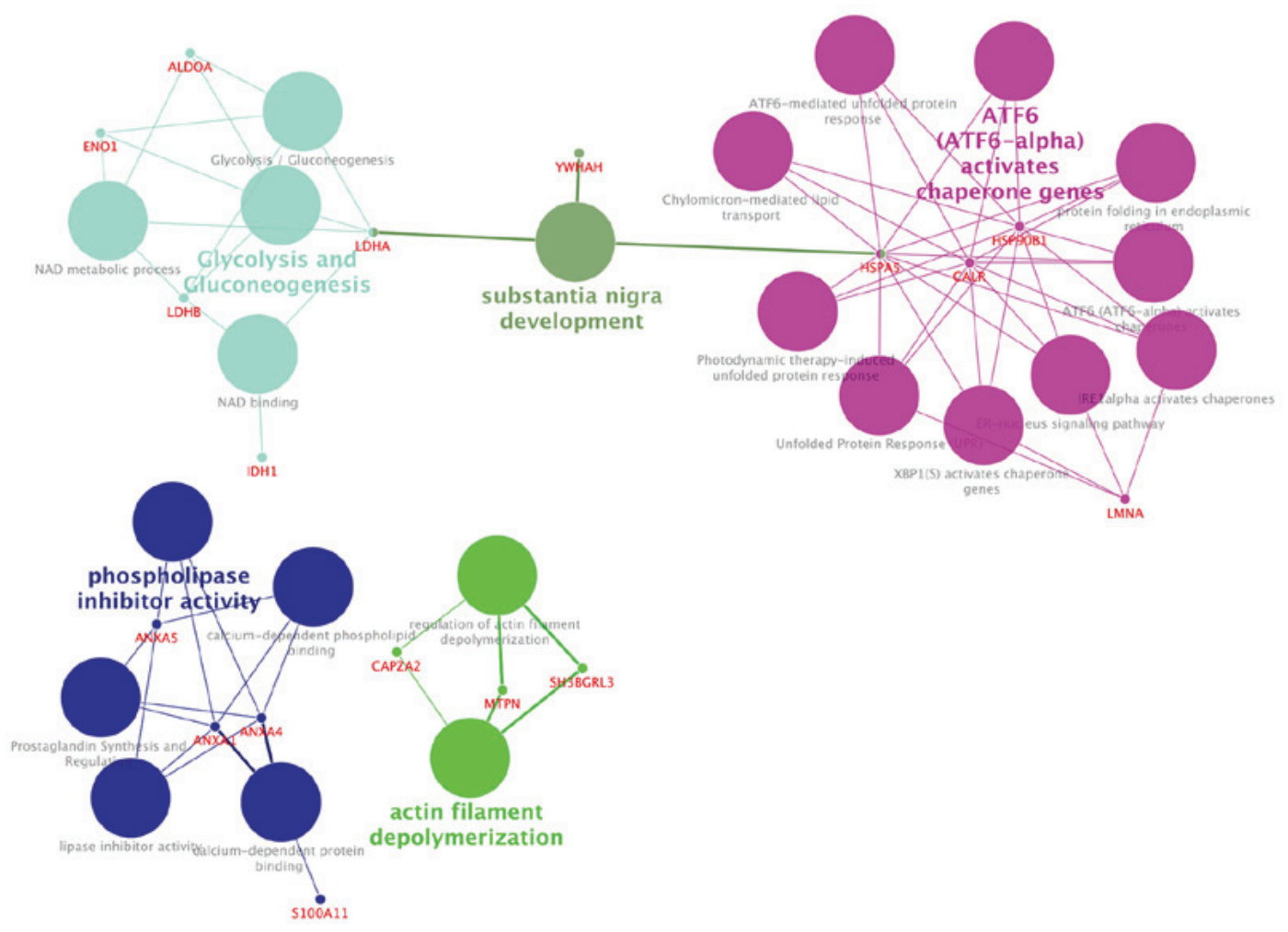

B

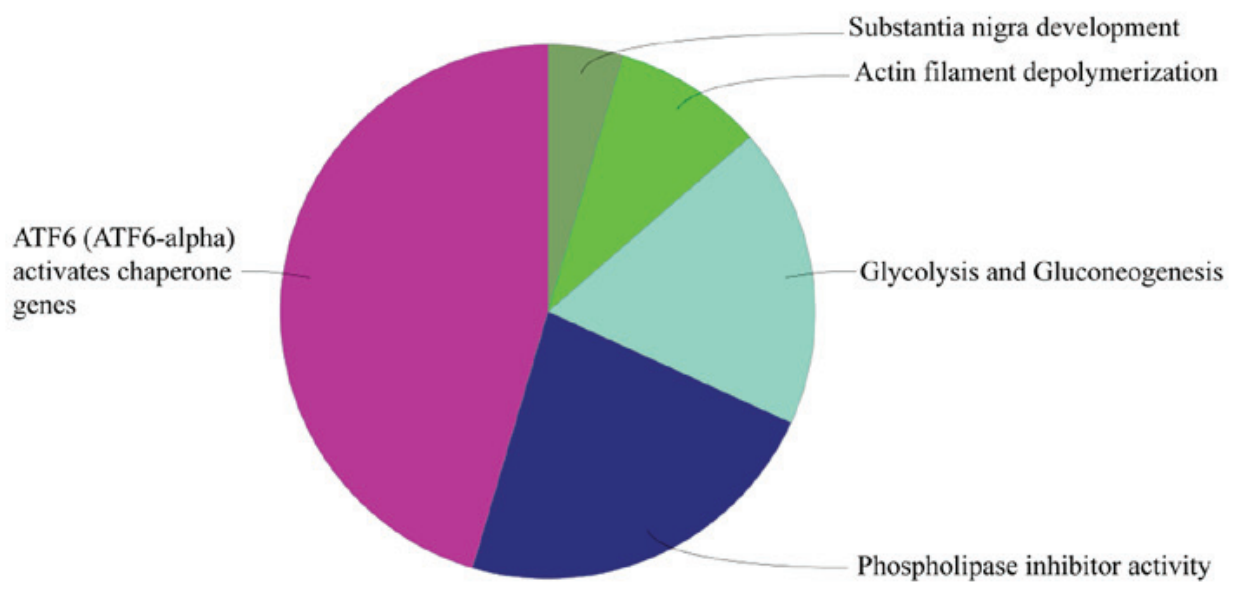

C

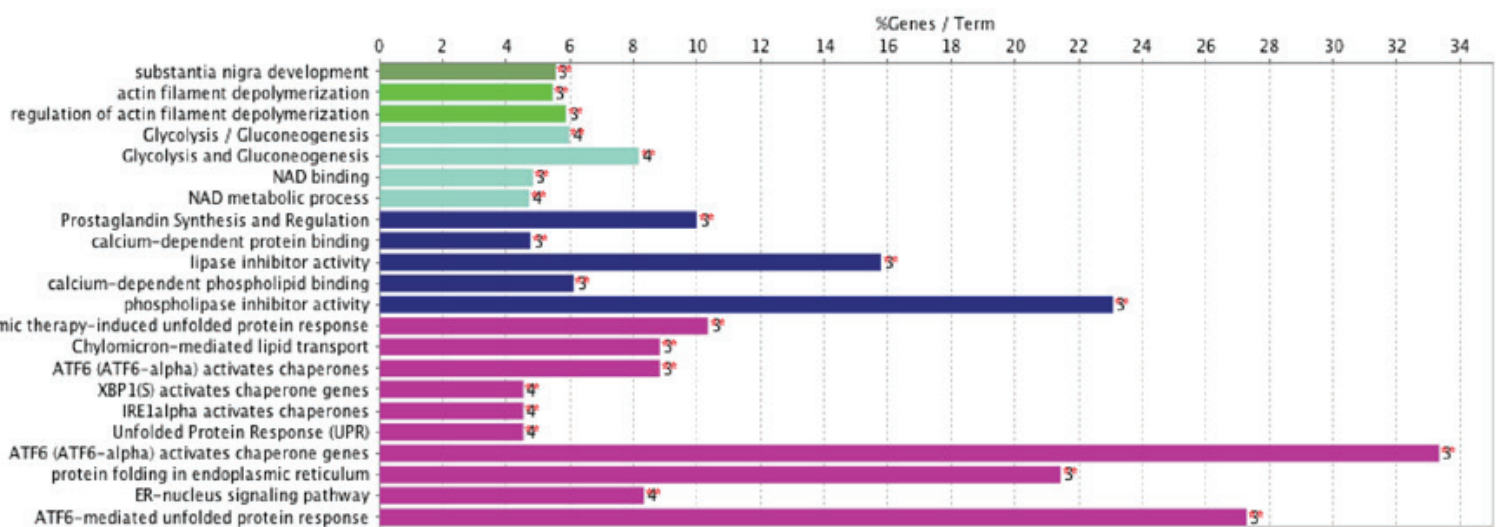

Figure 5. Enriched GO network groups using the ClueGo and CluePedia plugins of Cytoscape. (A) Functionally grouped networks based on GO terms, Reactome, Kyoto Encyclopedia of Genes and Genomes and WikiPathways with terms as nodes linked based on their $\kappa$ score level ( $\geq 0.3)$. Only the most significant term in each group is presented using ClueGo. Associated proteins were visualized using CluePedia. (B) An overview chart with functional groups, including specific terms for the upregulated proteins in the osteosarcoma tissues. (C) GO/pathway terms specific for the upregulated proteins in the osteosarcoma tissues. The bars represent the number of genes associated with the terms. GO, gene ontology. 
A
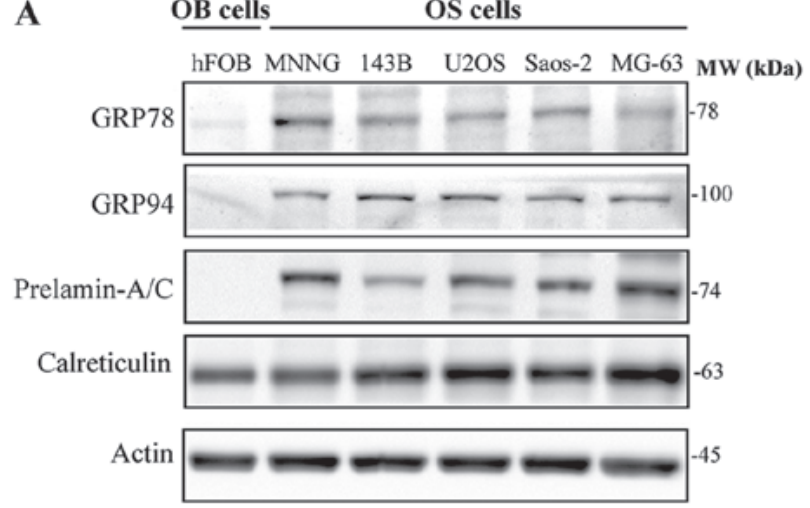

GRP78
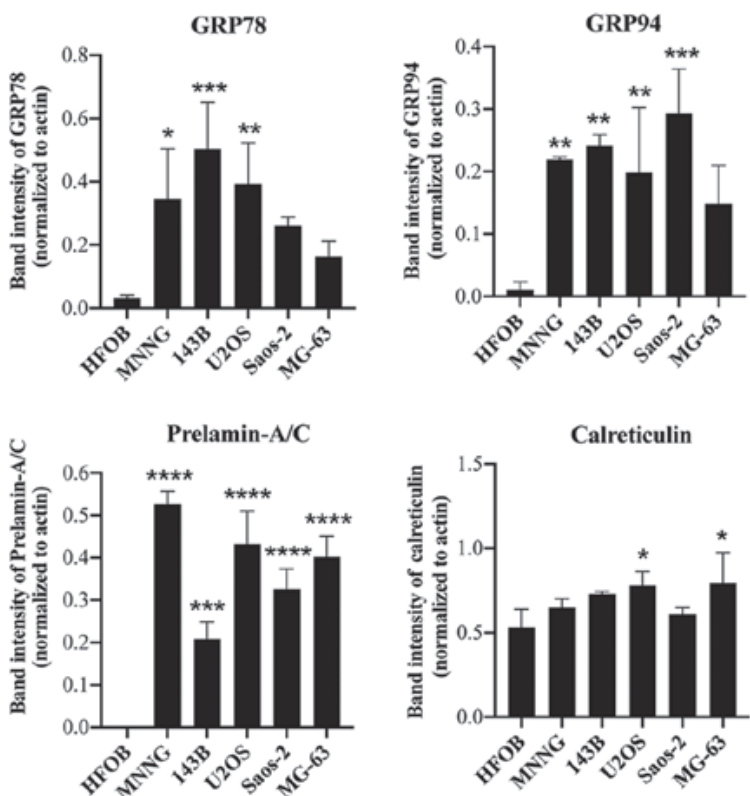

B

Primary OB cells $\quad$ Primary OS cells

OB1 $\quad$ OB2 2 OB3 $\quad$ OB4 $\mathrm{OB}^{2}$ OSP1 OSP2 OSP3 OSP4 OSP5 OSP6 MW (kDa)

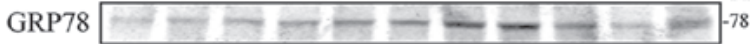

GRP94 $----\infty-\infty-\infty{ }^{-100}$

Prelamin-A/C $\square-\square=-7$

Calreticulin $=-6=0-63$

Actin $=-\mathrm{m}=\mathrm{W}$

GRP78

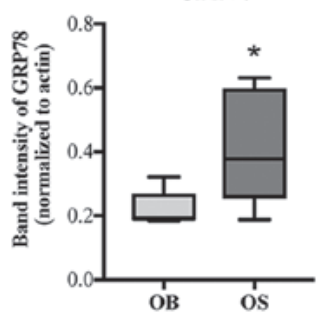

Prelamin-A/C
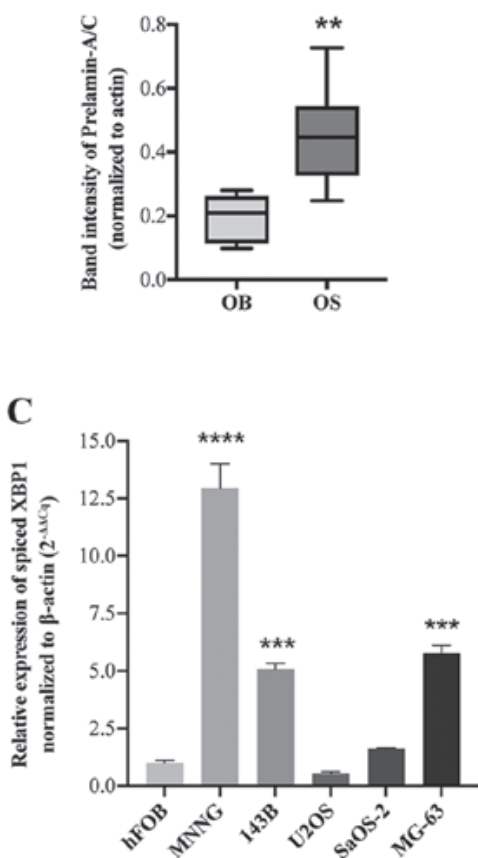

GRP94

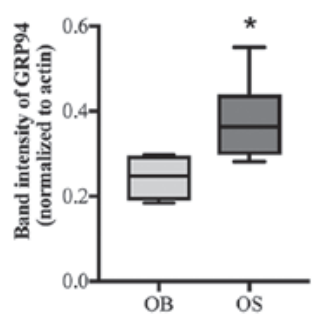

Calreticulin

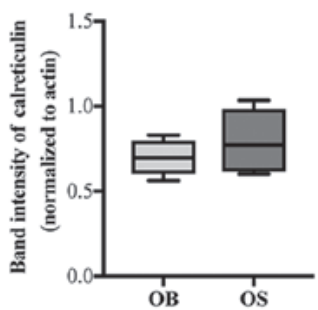

D

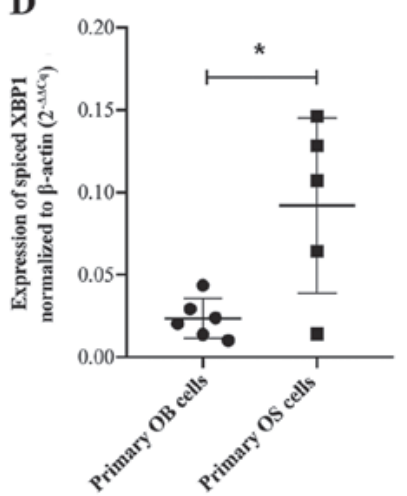

Figure 6. Expression of unfolded protein response-related proteins is upregulated in osteosarcoma cells. Immunoblots of GRP78, GRP94, calreticulin and prelamin-A/C in (A) osteosarcoma cell lines (MNNG/HOS, 143B, U2OS, Saos-2 and MG-63) compared with the osteoblastic cells (hFOB 1.19), and (B) primary osteosarcoma cells (OSP1-6) compared with primary osteoblastic cells (OB1-5). (C) Reverse transcription-quantitative polymerase chain reaction analysis of spliced XBP1 expression levels in osteoblastic cell line vs. osteosarcoma cell lines and (D) primary osteoblastic cells vs. primary osteosarcoma cells. Data are presented as means \pm standard deviation from three independent experiments. ${ }^{*} \mathrm{P}<0.05,{ }^{* *} \mathrm{P}<0.01,{ }^{* * *} \mathrm{P}<0.001$ and ${ }^{* * * * *} \mathrm{P}<0.0001$ compared to osteoblasts. GRP78, 78 kDa glucose-related protein; GRP94, endoplasmin; OSP, primary osteosarcoma cell; OB, primary osteoblastic cell; XBP1, X-box binding protein 1.

The results of the 2DE and LC-MS/MS in the present study revealed significant changes in the expression levels of various proteins from the osteosarcoma tissues compared with the soft callus. Using bioinformatics tools, the significantly enriched network groups identified in osteosarcoma included 'ATF6 (ATF6-alpha) activates chaperone genes', 'phospholipase inhibitor activity', 'glycolysis and gluconeogenesis', 'actin filament depolymerization' and 'substantial nigra development'. Among these functional groups, the majority of the upregulated proteins, including GRP78 (also known as BiP or HSP70 family protein 5), GRP94 (also known as heat shock protein $90 \mathrm{kDa} \beta$ member 1) and calreticulin (also known as ERp60 or GRP60), were related to the 'ATF6 (ATF6-alpha) activates chaperone genes' group, which is one of the three major endoplasmic reticulum (ER) stress sensors controlling the UPR pathway. In addition, elevated levels of prelamin-A/C were observed, which is a protein related to the XBP1 arm of the UPR pathway. The findings from the proteomics study were further validated by investigation of the levels of these UPR-related proteins in various types of samples, including 
A
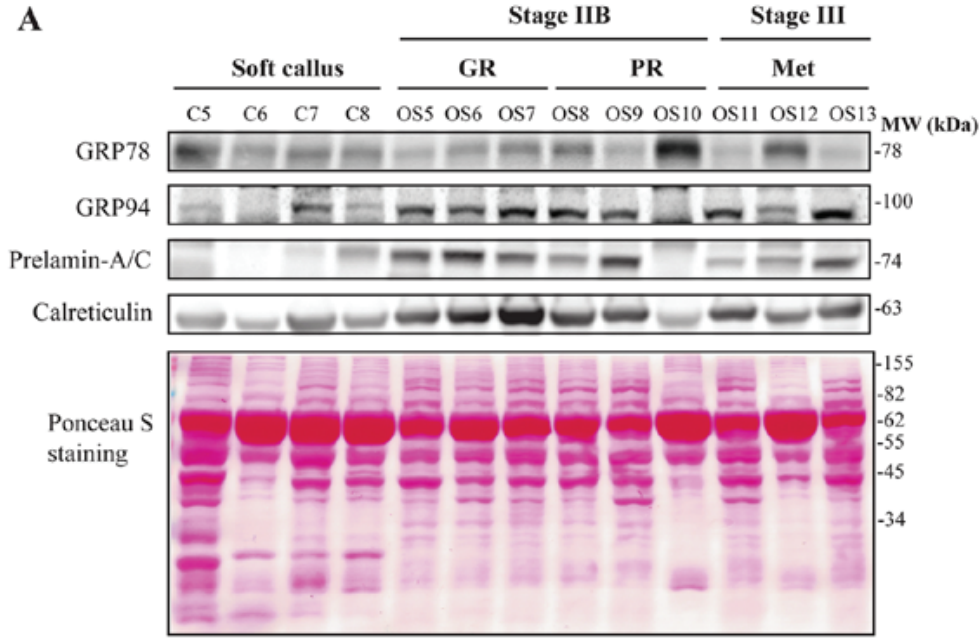

B
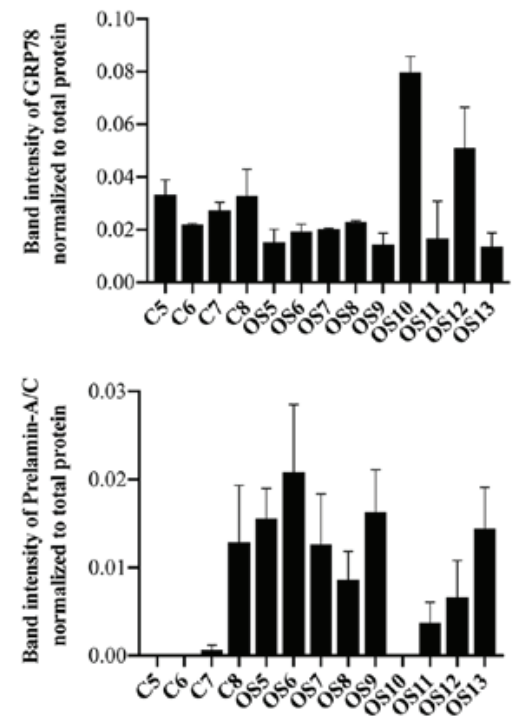
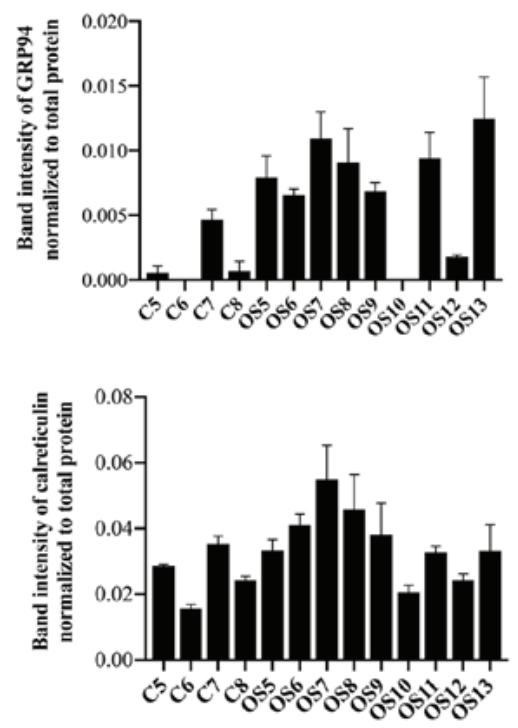

\section{C}
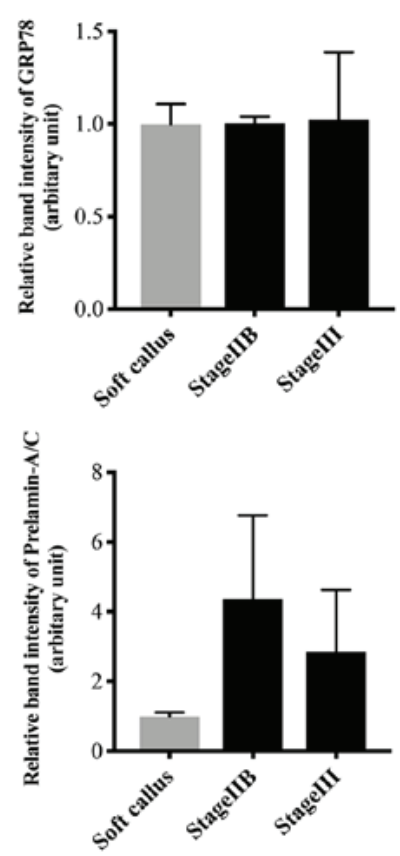
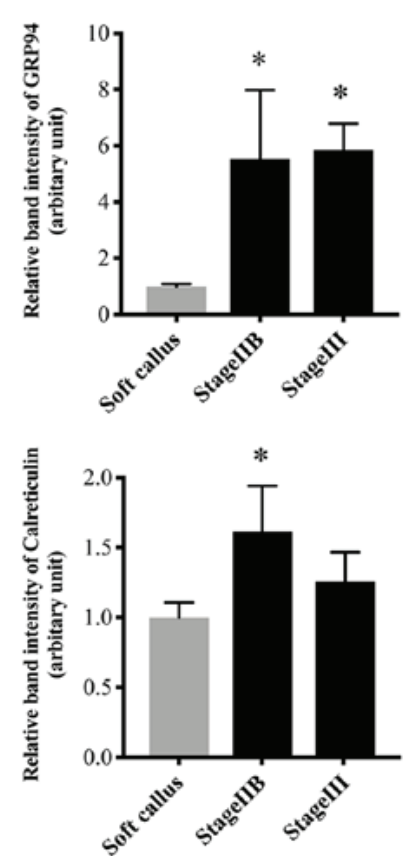

Figure 7. Expression of UPR-related proteins in soft callus (C5-C8) and osteosarcoma tissues (OS5-OS13), including patients with stage IIB (6 cases) and stage III (3 cases) disease. (A) Western blotting of GRP78, GRP94, prelamin-A/C and calreticulin in soft callus and osteosarcoma tissues. Total proteins, used as a loading control, were evaluated using Ponceau S staining. (B) Bar graphs demonstrating the levels of the UPR-related proteins normalized to total protein in individual samples. (C and D) Quantification and statistical analysis of the levels of the tested proteins in the soft callus and osteosarcoma tissues. Data are presented as means \pm standard deviation from three independent experiments. ${ }^{*} \mathrm{P}<0.05$ compared to the soft callus, or as indicated by brackets. UPR, unfolded protein response; GRP78, 78 kDa glucose-related protein; GRP94, endoplasmin; GR, good responders; PR, poor responders; Met, metastatic; C, soft callus control; OS, osteosarcoma. 


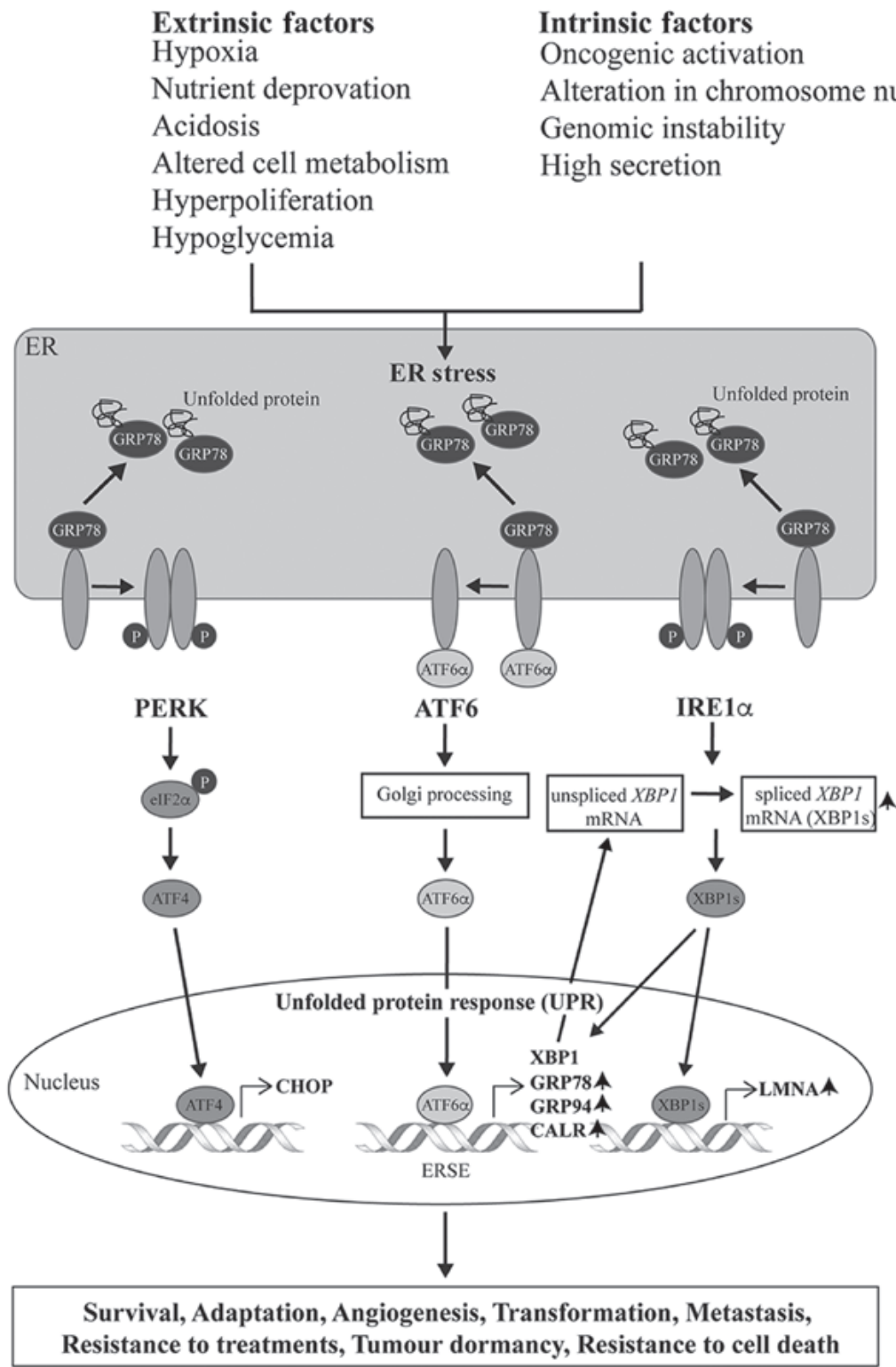

Figure 8. Diagram demonstrating the unfolded protein response pathway and downstream chaperone proteins. Upwards-pointing arrows next to protein names indicate upregulated proteins in osteosarcoma. ER, endoplasmic reticulum; GRP78, 78 kDa glucose-related protein; P, phosphorylated; PERK, PRKR-like ER kinase; ATF, activating transcription factor; IRE, inositol-requiring enzyme; CHOP, C/EBP homologous protein; XBP1, X-box binding protein 1; GRP94, endoplasmin; CALR, calreticulin; LMNA, lamin A/C.

osteosarcoma cell lines, patient-derived primary cells and an independent set of tissue samples. These results substantiated the data from the proteomics study and demonstrated that all of the proteins were upregulated in osteosarcoma.

The present study revealed overexpression of three key ER chaperone proteins, including two classical UPR markers, GRP78 and GRP94, in addition to a well-characterized chaperone, calreticulin. Accumulating evidence has demonstrated that elevated expression of these proteins in a wide range of cancer types results from activation of the UPR (26). Under intrinsic perturbations and hostile environments, cancer cells restore protein homeostasis (proteostasis), which is one of the hallmarks of cancer, in order to promote cancer cell transformation and progression $(27,28)$. The intrinsic factors include oncogenic activation, alteration in chromosome number, genomic instability, high secretion levels of proteins, and high levels of protein production $(29,30)$. Among the extrinsic factors are hypoxia, nutrient deprivation, acidosis, altered cell metabolism, hyperproliferation and hypoglycemia (31). These factors induce ER stress, which is the result of an accumulation of misfolded proteins in the ER lumen (32). In response to ER stress, cancer cells activate the UPR, an adaptive mechanism to recover the ER protein-folding environment and proteostasis that assist cancer cell survival (31). A large amount of evidence suggests that activation of the UPR serves important roles in numerous aspects of cancer development and progression, including cell survival, angiogenesis, metastasis, resistance to treatment, adaptation, transformation and tumor dormancy (33). A diagram of the UPR pathway is provided in Fig. 8.

GRP78 is the ER master chaperone, which acts as a major regulator of the UPR (34). In non-stressed conditions, GRP78 inactivates the UPR by binding to all three ER stress inducers, PRKR-like ER kinase (PERK), inositol-requiring enzyme 1 (IRE1) and ATF6 (35). Upon ER stress, GRP78 
activates the UPR pathways by dissociating from the stress inducers and then binding to misfolded proteins, which accumulate in the ER (Fig. 8). Free ATF6 subsequently triggers downstream signaling to increase ER protein folding capacity and ER-associated protein degradation through the transcription of various related genes that encode for the chaperone proteins, including GRP78, GRP94, calreticulin and XBP1 (34,36-38). As a consequence, during tumorigenesis, expression of GRP78 and other ER chaperones is enhanced by the UPR. Notably, Luo et al (39) demonstrated that inhibition of GRP78 upregulates ATF4 and the pro-apoptotic factor C/EBP homologous protein (CHOP) and sensitizes osteosarcoma cells to bortezomib, an FDA-approved proteasome inhibitor. Luo et al (39) also reported that upon ER stress induction, elevated expression of GRP78 protects against osteosarcoma cell death through diminishing the activity of CHOP by promoting ubiquitinating degradation of $\mathrm{CHOP}$ protein.

Furthermore, the present study revealed an upregulation of the spliced form of XBP1 mRNA, XBP1s, in osteosarcoma cells compared with osteoblastic cells. This finding confirmed that the ATF6 pathway was induced in osteosarcoma, because it is well known that expression of XBP1 mRNA is a downstream target of ATF6 and XBP1s (Fig. 8) (38). Significant levels of XBP1 mRNA are essential for subsequent splicing processes activated by the IRE1 $\alpha$-dependent pathway (40). The spliced form of XBP1 is a more stable and potent transcription activator than the un-spliced XBP1 (XBP1u). As a consequence, XBP1s effectively induces transcription of various UPR-related genes and chaperones.

Not only was GRP78 overexpressed in osteosarcoma in the present study, elevated levels of GRP78 were observed in chemonaïve tissues of patients with osteosarcoma who responded poorly to chemotherapy compared with good responders, suggesting an association of GRP78 with intrinsic drug resistance. Accumulating evidence has demonstrated an association between GRP78 and pre-existing resistance mechanisms in various types of cancer. For example, a high expression level of GRP78 in chemonaïve cancer tissues has been identified to be associated with subsequent development of chemoresistance $(41,42)$. Furthermore, an enhanced level of GRP78 has been demonstrated to be strongly correlated with an acquired chemoresistance mechanism in cancer $(43,44)$. Notably, Xia et al (45) demonstrated the role of GRP78 in acquired chemoresistance of osteosarcoma cell lines; DOX treatment induced P-glycoprotein (P-gp) and GRP78 expression, as well as activation of the serine/threonine kinase Akt, both in vitro and in vivo. The results also revealed an important role of GRP78 in full Akt activity, in which GRP78 activates Akt and enhances Akt-mediated P-gp expression in response to DOX treatment. In addition, DOX-resistant osteosarcoma lines that express higher levels of P-gp markedly stimulate the resistance mechanism.

Overexpression of proteins involved with the UPR pathway, particularly in the ATF6 arm, suggest that the activation of ATF6 signaling may contribute to oncogenesis events in osteosarcoma. Schewe and Aguirre-Ghiso (46) reported a potential role of ATF6 in tumor dormancy and chemoresistance. They demonstrated that transcription factor ATF6 $\alpha$ is an essential survival factor exclusively for quiescent cells. Silencing of the ATF6 gene reduces survival and resistance to rapamycin in dormant squamous carcinoma cells in vivo. The findings of the present study suggest that upregulation of important proteins in the ATF6 pathway may contribute to chemoresistance and tumor dormancy phenotypes in osteosarcoma cells. These findings also suggest a possible strategy for targeting UPR components for the treatment of osteosarcoma.

One of the most promising strategies is to use an agent that augments ER stress, shifting it from an adaptive to an apoptotic mechanism. Prolonged activation of UPR signals can trigger pro-apoptotic events that eliminate damaged cells. Proteasome inhibitors are key players in this respect, since the attenuation of proteasome activity effectively induces apoptosis in UPR-dependent tumors through various mechanisms (29). Prevention of proteasomal degradation results in an overwhelming accumulation of misfolded proteins in the cytosol, which induces ER stress, overcomes the UPR adaptive mechanism, and ultimately triggers apoptosis of cells. The antitumor effect of bortezomib, a FDA-approved proteasome inhibitor for the treatment of multiple myeloma, has been tested in osteosarcoma (47). Bortezomib was demonstrated to inhibit cell growth through the apoptosis pathway both in vitro and in vivo. A phase II clinical trial of bortezomib was conducted in patients with advanced or metastatic sarcoma, including adult patients with osteosarcoma (NCT00027716). Direct inhibition of GRP78 is another promising approach. In a phase I clinical trial, the GRP78 monoclonal immunoglobulin M antibody PAT-SM6 was used as a single agent in relapsed or refractory multiple myeloma (48). The results revealed that PAT-SM6 was well tolerated with modest clinical activity in the patients.

Limitations of the present study are the rarity of this type of tumor and the small number of patients. Future work will need to be performed in a larger cohort of osteosarcoma patients to validate these findings of association of UPR-related proteins and chemo-resistance.

In conclusion, the present study identified a number of pathways that are aberrantly regulated in osteosarcoma. The most significant one is an activation of the adaptive mechanism, the UPR, induced by ER stress. This finding suggests a potential role for therapeutic agents that target the UPR pathway in the treatment of osteosarcoma, inducing a shift to pro-apoptotic events and/or acting on specific key proteins.

\section{Acknowledgements}

The authors would also like to express their sincere thanks to Dr G. Lamar Robert, and Associate Professor Dr Chongchit Sripun Robert, for critical review of our manuscript, and Areerak Phanphaisarn for help with for statistical analysis. Part of this study was presented at the 9th Asia-Oceania Human Proteome Organization (AOHUPO) Conference (2018), as a poster presentation with interim findings.

\section{Funding}

This study was supported by the National Science and Technology Development Agency (grant no. P-15-50265), the Faculty of Medicine Chiang Mai University, the National Research University fund, and the Musculoskeletal Science and Translational Research Center. 


\section{Availability of data and materials}

The datasets used during the present study are available from the corresponding author upon reasonable request.

\section{Authors' contributions}

DP and PC designed the experiments. JSe performed the histological evaluation of osteosarcoma tissue and soft tissue callus. PS and PD performed the experiments in 2DE. NS performed the experiments in western blotting analysis. PT and JK performed primary cell extraction and characterization. DC performed the LC-MS/MS. PS and PT analyzed the proteomics data. PC performed network analysis, generated the data, and assembled the figures and tables. CS and JSv reviewed and edited the manuscript. DP and PC wrote the manuscript. All authors have reviewed and approved the final version of the manuscript.

\section{Ethics approval and consent to participate}

The protocol involving human clinical samples was approved by the Ethics Committee of the Faculty of Medicine, Chiang Mai University. Written informed consent was obtained from all patients.

\section{Patient consent for publication}

Not applicable.

\section{Competing interests}

The authors declare that they have no competing interests.

\section{References}

1. Settakorn J, Lekawanvijit S, Arpornchayanon O, Rangdaeng S Vanitanakom P, Kongkarnka S, Cheepsattayakorn R, Ya-In C and Thorner PS: Spectrum of bone tumors in Chiang Mai University Hospital, Thailand according to WHO classification 2002: A study of 1,001 cases. J Med Assoc Thai 89: 780-787, 2006.

2. Friebele JC, Peck J, Pan X, Abdel-Rasoul M and Mayerson JL: Osteosarcoma: A meta-analysis and review of the literature. Am J Orthop (Belle Mead NJ) 44: 547-553, 2015.

3. Whelan JS, Bielack SS, Marina N, Smeland S, Jovic G, Hook JM, Krailo M, Anninga J, Butterfass-Bahloul T, Böhling T, et al EURAMOS collaborators: EURAMOS-1, an international randomised study for osteosarcoma: Results from pre-randomisation treatment. Ann Oncol 26: 407-414, 2015.

4. Chen X, Bahrami A, Pappo A, Easton J, Dalton J, Hedlund E, Ellison D, Shurtleff S, Wu G, Wei L, et al; St. Jude Children's Research Hospital-Washington University Pediatric Cancer Genome Project: Recurrent somatic structural variations contribute to tumorigenesis in pediatric osteosarcoma. Cell Rep 7: 104-112, 2014.

5. Botter SM, Neri D and Fuchs B: Recent advances in osteosarcoma. Curr Opin Pharmacol 16: 15-23, 2014.

6. Chaiyawat P, Pruksakorn D, Phanphaisarn A, Teeyakasem P, Klangjorhor $\mathbf{J}$ and Settakorn J: Expression patterns of class I histone deacetylases in osteosarcoma: A novel prognostic marker with potential therapeutic implications. Mod Pathol 31: 264-274, 2018.

7. Xie C, Wu B, Chen B, Shi Q, Guo J, Fan Z and Huang Y: Histone deacetylase inhibitor sodium butyrate suppresses proliferation and promotes apoptosis in osteosarcoma cells by regulation of the MDM2-p53 signaling. Onco Targets Ther 9: 4005-4013, 2016.
8. Watanabe K, Okamoto K and Yonehara S: Sensitization of osteosarcoma cells to death receptor-mediated apoptosis by HDAC inhibitors through downregulation of cellular FLIP. Cell Death Differ 12: 10-18, 2005.

9. Rao-Bindal K, Koshkina NV, Stewart J and Kleinerman ES: The histone deacetylase inhibitor, MS-275 (entinostat), downregulates c-FLIP, sensitizes osteosarcoma cells to FasL, and induces the regression of osteosarcoma lung metastases. Curr Cancer Drug Targets 13: 411-422, 2013.

10. Zhu S, Denman CJ, Cobanoglu ZS, Kiany S, Lau CC, Gottschalk SM, Hughes DP, Kleinerman ES and Lee DA: The narrow-spectrum HDAC inhibitor entinostat enhances NKG2D expression without NK cell toxicity, leading to enhanced recognition of cancer cells. Pharm Res 32: 779-792, 2015.

11. Li Y, Liang Q, Wen YQ, Chen LL, Wang LT, Liu YL, Luo CQ, Liang HZ, Li MT and Li Z: Comparative proteomics analysis of human osteosarcomas and benign tumor of bone. Cancer Genet Cytogenet 198: 97-106, 2010.

12. Rao UN, Hood BL, Jones-Laughner JM, Sun M and Conrads TP: Distinct profiles of oxidative stress-related and matrix proteins in adult bone and soft tissue osteosarcoma and desmoid tumors: A proteomics study. Hum Pathol 44: 725-733, 2013.

13. Einhorn TA and Gerstenfeld LC: Fracture healing: Mechanisms and interventions. Nat Rev Rheumatol 11: 45-54, 2015.

14. Murao H, Yamamoto K, Matsuda S and Akiyama H: Periosteal cells are a major source of soft callus in bone fracture. J Bone Miner Metab 31: 390-398, 2013.

15. Han W, He W, Yang W, Li J, Yang Z, Lu X, Qin A and Qian Y: The osteogenic potential of human bone callus. Sci Rep 6: 36330, 2016.

16. Srisomsap C, Sawangareetrakul P, Subhasitanont P, Panichakul T, Keeratichamroen S, Lirdprapamongkol K, Chokchaichamnankit D, Sirisinha S and Svasti J: Proteomic analysis of cholangiocarcinoma cell line. Proteomics 4: 1135-1144, 2004.

17. Herosimczyk A, Dejeans N, Sayd T, Ozgo M, Skrzypczak WF and Mazur A: Plasma proteome analysis: 2D gels and chips. J Physiol Pharmacol 57 (Suppl 7): 81-93, 2006.

18. Zhang B, Kirov S and Snoddy J: WebGestalt: An integrated system for exploring gene sets in various biological contexts. Nucleic Acids Res 33: W741-W748, 2005.

19. Shannon P, Markiel A, Ozier O, Baliga NS, Wang JT, Ramage D, Amin N, Schwikowski B and Ideker T: Cytoscape: A software environment for integrated models of biomolecular interaction networks. Genome Res 13: 2498-2504, 2003.

20. Lotia S, Montojo J, Dong Y, Bader GD and Pico AR: Cytoscape app store. Bioinformatics 29: 1350-1351, 2013.

21. Pruksakorn D, Teeyakasem P, Klangjorhor J, Chaiyawat $\mathrm{P}$, Settakorn J, Diskul-Na-Ayudthaya P, Chokchaichamnankit D, Pothacharoen P and Srisomsap C: Overexpression of KH-type splicing regulatory protein regulates proliferation, migration, and implantation ability of osteosarcoma. Int J Oncol 49: 903-912, 2016.

22. van Schadewijk A, van't Wout EF, Stolk J and Hiemstra PS: A quantitative method for detection of spliced X-box binding protein-1 (XBP1) mRNA as a measure of endoplasmic reticulum (ER) stress. Cell Stress Chaperones 17: 275-279, 2012.

23. Livak KJ and Schmittgen TD: Analysis of relative gene expression data using real-time quantitative PCR and the 2(-Delta Delta C(T)) method. Methods 25: 402-408, 2001.

24. Schindeler A, McDonald MM, Bokko P and Little DG: Bone remodeling during fracture repair: The cellular picture. Semin Cell Dev Biol 19: 459-466, 2008.

25. Mörike M, Schulz M, Nerlich A, Koschnik M, Teller WM, Vetter U and Brenner RE: Expression of osteoblastic markers in cultured human bone and fracture callus cells. J Mol Med (Berl) 73: 571-575, 1995.

26. Luo B and Lee AS: The critical roles of endoplasmic reticulum chaperones and unfolded protein response in tumorigenesis and anticancer therapies. Oncogene 32: 805-818, 2013.

27. Hanahan D and Weinberg RA: Hallmarks of cancer: The next generation. Cell 144: 646-674, 2011.

28. Obacz J, Avril T, Le Reste PJ, Urra H, Quillien V, Hetz C and Chevet E: Endoplasmic reticulum proteostasis in glioblastoma-From molecular mechanisms to therapeutic perspectives. Sci Signal 10: 10, 2017.

29. Wang M and Kaufman RJ: The impact of the endoplasmic reticulum protein-folding environment on cancer development. Nat Rev Cancer 14: 581-597, 2014.

30. Dejeans N, Manié S, Hetz C, Bard F, Hupp T, Agostinis P, Samali A and Chevet E: Addicted to secrete - novel concepts and targets in cancer therapy. Trends Mol Med 20: 242-250, 2014. 
31. Ma Y and Hendershot LM: The role of the unfolded protein response in tumour development: Friend or foe? Nat Rev Cancer 4: 966-977, 2004.

32. Hetz C: The unfolded protein response: Controlling cell fate decisions under ER stress and beyond. Nat Rev Mol Cell Biol 13: 89-102, 2012.

33. Dufey E, Urra $\mathrm{H}$ and Hetz C: ER proteostasis addiction in cancer biology: Novel concepts. Semin Cancer Biol 33: 40-47, 2015.

34. Lee AS: Glucose-regulated proteins in cancer: Molecular mechanisms and therapeutic potential. Nat Rev Cancer 14: 263-276, 2014.

35. Wang M, Wey S, Zhang Y, Ye R and Lee AS: Role of the unfolded protein response regulator GRP78/BiP in development, cancer, and neurological disorders. Antioxid Redox Signal 11: 2307-2316, 2009.

36. Chang SC, Erwin AE and Lee AS: Glucose-regulated protein (GRP94 and GRP78) genes share common regulatory domains and are coordinately regulated by common trans-acting factors. Mol Cell Biol 9: 2153-2162, 1989.

37. Yamamoto K, Sato T, Matsui T, Sato M, Okada T, Yoshida H, Harada A and Mori K: Transcriptional induction of mammalian ER quality control proteins is mediated by single or combined action of ATF6alpha and XBP1. Dev Cell 13: 365-376, 2007.

38. Yoshida H, Matsui T, Yamamoto A, Okada T and Mori K: XBP1 mRNA is induced by ATF6 and spliced by IRE1 in response to ER stress to produce a highly active transcription factor. Cell 107: 881-891, 2001.

39. Luo J, Xia Y, Luo J, Li J, Zhang C, Zhang H, Ma T, Yang L and Kong L: GRP78 inhibition enhances ATF4-induced cell death by the deubiquitination and stabilization of CHOP in human osteosarcoma. Cancer Lett 410: 112-123, 2017.

40. Lee K, Tirasophon W, Shen X, Michalak M, Prywes R, Okada T, Yoshida H, Mori K and Kaufman RJ: IRE1-mediated unconventional mRNA splicing and S2P-mediated ATF6 cleavage merge to regulate XBP1 in signaling the unfolded protein response. Genes Dev 16: 452-466, 2002.
41. Lee E, Nichols P, Spicer D, Groshen S, Yu MC and Lee AS: GRP78 as a novel predictor of responsiveness to chemotherapy in breast cancer. Cancer Res 66: 7849-7853, 2006.

42. Mhaidat NM, Alzoubi KH, Almomani N and Khabour OF: Expression of glucose regulated protein 78 (GRP78) determines colorectal cancer response to chemotherapy. Cancer Biomark 15: 197-203, 2015.

43. Gifford JB, Huang W, Zeleniak AE, Hindoyan A, Wu H, Donahue TR and Hill R: Expression of GRP78, master regulator of the unfolded protein response, increases chemoresistance in pancreatic ductal adenocarcinoma. Mol Cancer Ther 15: 1043-1052, 2016.

44. Li W, Wang W, Dong H, Li Y, Li L, Han L, Han Z, Wang S, Ma D and Wang H: Cisplatin-induced senescence in ovarian cancer cells is mediated by GRP78. Oncol Rep 31: 2525-2534, 2014.

45. Xia YZ, Yang L, Xue GM, Zhang C, Guo C, Yang YW, Li SS, Zhang LY,GuoQL and Kong LY:Combining GRP78 suppression and MK2206-induced Akt inhibition decreases doxorubicin-induced P-glycoprotein expression and mitigates chemoresistance in human osteosarcoma. Oncotarget 7: 56371-56382, 2016.

46. Schewe DM and Aguirre-Ghiso JA: ATF6alpha-Rheb-mTOR signaling promotes survival of dormant tumor cells in vivo. Proc Natl Acad Sci USA 105: 10519-10524, 2008.

47. Shapovalov Y, Benavidez D, Zuch D and Eliseev RA: Proteasome inhibition with bortezomib suppresses growth and induces apoptosis in osteosarcoma. Int J Cancer 127: 67-76, 2010.

48. Rasche L, Duell J, Castro IC, Dubljevic V, Chatterjee M, Knop S, Hensel F, Rosenwald A, Einsele H, Topp MS, et al: GRP78-directed immunotherapy in relapsed or refractory multiple myeloma - results from a phase 1 trial with the monoclonal immunoglobulin M antibody PAT-SM6. Haematologica 100: 377-384, 2015.

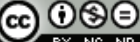

This work is licensed under a Creative Commons Attribution-NonCommercial-NoDerivatives 4.0 International (CC BY-NC-ND 4.0) License. 